\title{
Relation between ultrasound measurements and phase evolution in accelerated cementitious matrices
}

\author{
Renan P. Salvador ${ }^{\mathrm{a}, \mathrm{b}, 1}$, Sergio H. P. Cavalaro ${ }^{\mathrm{a}, 1}$, Ignacio Segura ${ }^{\mathrm{a}, \mathrm{c}}$, Margarita G. \\ Hernández ${ }^{\mathrm{d}}$, Javier Ranz ${ }^{\mathrm{d}}$, Antonio D. de Figueiredo ${ }^{\mathrm{e}}$
}

${ }^{a}$ Construction Engineering Department, Barcelona Tech, Polytechnic University of Catalonia, UPC, Jordi Girona 1-3, 08034, Barcelona, Spain.

${ }^{\mathrm{b}}$ CAPES Foundation, Ministry of Education of Brazil, Brasília - DF, 70040-020, Brazil.

${ }^{\mathrm{c}}$ Smart Engineering Ltd., Secretari Coloma 119, 08024, Barcelona, Spain.

d Institute of Physical and Information Technologies Leonardo Torres Quevedo (ITEFI), CSIC, C/ Serrano 114, 28006, Madrid, Spain.

${ }^{\text {e }}$ Civil Construction Engineering Department, Polytechnic School of University of São Paulo, Professor Almeida Prado, Trav. 2, 83, 05424-970, São Paulo, Brazil.

\begin{abstract}
This paper focuses on the characterization of setting and hardening of accelerated cementitious matrices by ultrasound propagation velocity, correlating these processes with chemical parameters and the phase evolution obtained by in situ XRD. Evolution of temperature and determination of setting times complemented this analysis. The technique employed provided a continuous monitoring of the setting and hardening of the hydrating matrix and was susceptible to changes in accelerator reactivity and phase composition. Results showed that ettringite formed by accelerator reaction improves the solid-phase interconnectivity and increases initial ultrasound velocity. P-wave propagation during the acceleration period is directly proportional to alite and $\mathrm{C}_{3} \mathrm{~A}$ degrees of hydration. The influence of AFm phases to increase ultrasound velocity is stronger than ettringite and C-S-H. Based on an extensive statistical analysis, multivariate linear regressions were established between ultrasound velocity and the main chemical properties influencing its evolution, leading to a better comprehension of how these parameters are related.
\end{abstract}

Keywords: Ultrasonic measurements, Setting time, Accelerator, Hydration, Sprayed concrete.

\footnotetext{
${ }^{1}$ Corresponding authors. Tel.: +34 934054247, Fax: +34 934011036.

E-mail addresses: renan.picolo@upc.edu (R Salvador); sergio.pialarissi@upc.edu (S Cavalaro).
} 


\section{Introduction}

Ultrasound measurements are a versatile tool to characterize cementitious matrices. Several ultrasound techniques have been used to evaluate the setting process [1-3], mechanical strength [4,5], porosity [6-9], permeability [6-9] and durability $[10,11]$ of pastes, mortars and concrete during the past years. The influence of different superplasticizers and additions on early strength development has been analyzed by [12-15].

This technique may also be used to characterize the early age hydration reactions in cementitious matrices containing set accelerators $[16,17]$, in which the determination of initial stiffness and of early age strength are crucial for an adequate application. It may provide a continuous evaluation of the setting and hardening processes of these mixes, being more representative than Vicat, needle and pin penetration tests, which are discontinuous and have a limited application range [18].

Table 1 summarizes the most recent work conducted in the field of ultrasound measurements applied to cementitious matrices. Notice that the majority of the studies focus on the characterization of conventional concrete by ultrasound propagation velocity and only a few also assess the kinetics and mechanisms of hydration. None of them evaluates how accelerated chemical reactions and the resulting microstructure influence the propagation of ultrasound waves from a quantitative standpoint.

Table 1 - Summary of recent studies on ultrasound measurements applied to cementitious matrices.

\begin{tabular}{c|c|c|c|c|c|c}
\hline \multirow{2}{*}{ Reference } & \multicolumn{2}{|c|}{ Samples tested } & \multicolumn{3}{c|}{ Characterization } & $\begin{array}{c}\text { Quantitative } \\
\text { relation between } \\
\text { ultrasound and } \\
\text { phase evolution }\end{array}$ \\
\cline { 2 - 7 } & Conventional & Accelerated & Ultrasound & Kinetics & Phase evolution & \\
\hline$[1,12,14,15]$ & $\bullet$ & & $\bullet$ & $\bullet$ & & \\
\hline$[2-10,13]$ & $\bullet$ & & $\bullet$ & & & \\
\hline$[11]$ & $\bullet$ & & $\bullet$ & & $\bullet$ & \\
\hline$[16]$ & & $\bullet$ & $\bullet$ & $\bullet$ & & \\
\hline$[17]$ & & $\bullet$ & $\bullet$ & & & \\
\hline This study & & $\bullet$ & $\bullet$ & $\bullet$ & & $\bullet$ \\
\hline
\end{tabular}

The lack of such relations may compromise the characterization of accelerated cementitious matrices and the applicability of ultrasound measurements in practice. 
Therefore, it is fundamental to better comprehend how the chemical reactions occurring when accelerators are added and the resulting phase evolution influence the overall response to ultrasound propagation throughout the whole hydration process. By doing so, a more complete characterization of the evolution of mechanical properties of the matrix at early ages may be achieved, improving the design and quality control.

The main objective of this study is to characterize the hydration behavior of accelerated cement pastes and mortars by ultrasound propagation velocity, correlating these measurements with the chemical parameters and phase evolution of the matrix from a quantitative standpoint. For that, an experimental program was conducted with two types of cement and four types of accelerator, either alkali-free or alkaline. The setting and hardening processes as well as the development of microstructure were monitored by ultrasound propagation velocity. Setting times were determined by the Vicat needle test. Kinetics and mechanisms of hydration were characterized by in situ $\mathrm{X}$-ray diffraction and evolution of temperature.

Multivariate regression analyses were conducted to correlate the changes in chemical properties of the matrix with those in the ultrasound velocity. For these analyses, the phase evolution during hydration and the chemical composition of cements and accelerators were considered as independent variables, whereas ultrasound velocity was the dependent variable.

Results indicate the main chemical parameters that influence microstructure development and ultrasound propagation velocity, explaining their origin. Correlations obtained are a simple useful tool to evaluate how the ultrasound velocity is affected by the chemical characteristics of the matrix. Therefore, this study promotes the rational use of this technique for characterization and control of matrices containing accelerators and for the evaluation of accelerator reactivity and compatibility with cement.

\section{Experimental methodology}

The experimental program was conducted at the Laboratory of Technology of Structures Luis Agulló at Universitat Politècnica de Catalunya (UPC) and at the Scientific and Technological Center from Universitat de Barcelona (CCIT-UB). Software development and data analysis for ultrasound wave propagation tests were 
executed at the Institute of Physical and Information Technologies Leonardo Torres Quevedo from the Spanish National Research Council.

Ultrasound measurements were performed in cement pastes and mortars. In cement pastes, kinetics and mechanisms of hydration are not influenced by aggregates and may provide a clearer evaluation of the chemical processes occurring during hydration. However, accelerated pastes are very reactive and shrinkage may limit the progression of the test. Therefore, accelerated mortars were also evaluated because aggregates provide more space for the precipitation of hydrated phases and reduce reaction rates. As a result, the negative effects of chemical shrinkage are minimized and a continuous monitoring of setting and hardening may be obtained.

In the following sections, materials, production processes and tests performed are described.

\subsection{Materials}

Two types of Portland cement (CEM I 52.5R and CEM II/A-L 42.5R) were used in this study. These cements were selected among the commonly used in sprayed concrete applications. CEM II/A-L is widely used in countries from northern Europe, while CEM I is common in Spain and countries from Asia and America. Table 2 and Table 3 show their mineralogical composition determined by XRD-Rietveld refinement and their chemical composition determined by XRF spectrometry, respectively. Besides, Table 4 summarizes their chemical and physical properties.

Table 2 - Mineralogical compositions of cements determined by XRD / Rietveld refinement.

\begin{tabular}{ccc}
\hline Compound & CEM I (\%) & CEM II/A-L (\%) \\
\hline $\mathrm{C}_{3} \mathrm{~S}$ & 58.3 & 51.7 \\
\hline $\mathrm{C}_{2} \mathrm{~S}$ & 11.2 & 6.7 \\
\hline $\mathrm{C}_{3} \mathrm{~A}_{\mathrm{c}}$ & 4.1 & 2.9 \\
\hline $\mathrm{C}_{3} \mathrm{~A}_{0}$ & 0.6 & 0.7 \\
\hline $\mathrm{C}_{4} \mathrm{AF}$ & 13.4 & 14.8 \\
\hline $\mathrm{CaO}$ & 1.1 & 1.2 \\
\hline $\mathrm{Ca}(\mathrm{OH})_{2}$ & 1.7 & 0.7 \\
\hline $\mathrm{CaCO}$ & 1.9 & 11.3 \\
\hline
\end{tabular}




\begin{tabular}{ccc}
\hline $\mathrm{CaSO}_{4} .2 \mathrm{H}_{2} \mathrm{O}$ & 2.1 & 0.7 \\
\hline $\mathrm{CaSO}_{4} .0 .5 \mathrm{H}_{2} \mathrm{O}$ & 4.4 & 5.3 \\
\hline $\mathrm{K}_{2} \mathrm{SO}_{4}$ & - & 0.5 \\
\hline $\mathrm{K}_{2} \mathrm{Ca}\left(\mathrm{SO}_{4}\right)_{2} \cdot \mathrm{H}_{2} \mathrm{O}$ & 1.1 & - \\
\hline $\mathrm{MgO}$ & - & 0.6 \\
\hline $\mathrm{MgCO}_{3}$ & - & 3.1 \\
\hline Total sum & 100.0 & 100.0 \\
\hline
\end{tabular}

Table 3 - Chemical compositions of cements determined by XRF spectrometry.

\begin{tabular}{ccc}
\hline Compound & CEM I (\%) & CEM II/A-L (\%) \\
\hline $\mathrm{LOI}$ & 2.88 & 6.42 \\
\hline $\mathrm{CaO}$ & 62.62 & 62.48 \\
\hline $\mathrm{SiO}_{2}$ & 19.89 & 17.61 \\
\hline $\mathrm{Al}_{2} \mathrm{O}_{3}$ & 4.74 & 4.04 \\
\hline $\mathrm{Fe}_{2} \mathrm{O}_{3}$ & 3.26 & 3.53 \\
\hline $\mathrm{SO}_{3}$ & 3.53 & 3.21 \\
\hline $\mathrm{MgO} \mathrm{K}_{2} \mathrm{O}$ & 1.95 & 1.69 \\
\hline $\mathrm{Na}_{2} \mathrm{O}$ & $0.99(0.98)^{\mathrm{a}}$ & $0.83(0.62)^{\mathrm{a}}$ \\
\hline Minor components & $0.13(0.011)^{\mathrm{a}}$ & $0.13(0.035)^{\mathrm{a}}$ \\
\hline Total sum & 0.11 & 0.09 \\
\hline
\end{tabular}

${ }^{\mathrm{a}} \mathrm{K}_{2} \mathrm{O}$ and $\mathrm{Na}_{2} \mathrm{O}$ readily soluble, determined by ion chromatography from a solution extracted from a cement suspension with w/c equal to 9 [19].

Table 4 - Chemical and physical properties of cements.

\begin{tabular}{ccc}
\hline Property & CEM I & CEM II/A-L \\
\hline Total heat of hydration $^{\mathrm{a}}(\mathrm{J} / \mathrm{g})$ & 433.0 & 381.0 \\
\hline $\mathrm{C}_{3} \mathrm{~A} / \mathrm{SO}_{3}$ molar ratio & 0.39 & 0.33 \\
\hline Insoluble residue $(\%)$ & 2.74 & 2.90 \\
\hline Specific surface BET $\left(\mathrm{m}^{2} / \mathrm{g}\right)$ & 2.96 & 1.88 \\
\hline $\mathrm{d}_{50}(\mu \mathrm{m})$ & 11.4 & 15.7 \\
\hline
\end{tabular}

${ }^{a}$ The total heat of hydration was estimated from the mineralogical composition of the cement, determined by XRD, as the relative sum of the heats of hydration of the individual phases $\left(\mathrm{C}_{3} \mathrm{~S}: 510 \mathrm{~J} / \mathrm{g} ; \mathrm{C}_{2} \mathrm{~S}: 260 \mathrm{~J} / \mathrm{g}\right.$; $\mathrm{C}_{3} \mathrm{~A}: 1100 \mathrm{~J} / \mathrm{g} ; \mathrm{C}_{4} \mathrm{AF}: 410 \mathrm{~J} / \mathrm{g}$ [20]). 
For the fabrication of mortars, standard silica sand following the requirements from UNE EN 196-1:2005 [21] was used. Distilled water and a superplasticizer based on a polycarboxylate solution (34\% of solid content) were used to prepare all pastes and mortars.

Three alkali-free accelerators composed by aluminum hydroxysulfate solutions were selected to cover the types commonly found in practice. They contain different aluminum/sulfate balances and their nomenclature corresponds to ' $\mathrm{AKF} \mathrm{Al}_{2} \mathrm{O}_{3} / \mathrm{SO}_{4}{ }^{2-}$ molar ratio'. An alkaline accelerator based on sodium aluminate, identified by 'ALK', was also employed. Properties and characteristics of accelerators are presented in Table 5 .

Table 5 - Properties of accelerators.

\begin{tabular}{ccccc}
\hline Characteristic & AKF 0.38 & AKF 0.42 & AKF 0.61 & ALK \\
\hline Solid content (\%) & 40.0 & 34.5 & 47.6 & 43.0 \\
\hline $\mathrm{Al}_{2} \mathrm{O}_{3}$ content $(\%)$ & 11.2 & 10.1 & 13.5 & 24.0 \\
\hline $\mathrm{SO}_{4}{ }^{2-}$ content $(\%)$ & 27.6 & 22.5 & 21.0 & - \\
\hline $\mathrm{Na}_{2} \mathrm{O}$ content $(\%)$ & - & & - & 19.0 \\
\hline $\mathrm{pH}$ at $20^{\circ} \mathrm{C}$ & 2.6 & 2.4 & 3.0 & $12.0^{\mathrm{a}}$ \\
\hline $\mathrm{Al}_{2} \mathrm{O}_{3} / \mathrm{SO}_{4}{ }^{2-}$ molar ratio & 0.38 & 0.42 & 0.61 & - \\
\hline $\mathrm{Stabilizing} \mathrm{agent}^{2}$ & inorganic silicate & organic acid & organic acid & - \\
\hline
\end{tabular}

${ }^{\text {a }}$ Solution at $1.0 \%$.

\subsection{Composition and preparation of cement pastes and mortars}

All samples were prepared under controlled climatic conditions, at $20{ }^{\circ} \mathrm{C}$ and 50 $\%$ relative humidity. The nomenclature adopted to identify each composition follows the pattern 'matrix type'_cement type'_accelerator name and dosage'. Reference samples do not contain accelerators and are named by 'matrix type'_cement type'_REF. In total, 24 different compositions were evaluated in this work.

\subsubsection{Pastes}


Cement pastes were composed by cement, a fixed water/cement (w/c) ratio equal to 0.45 and $1.0 \%$ of superplasticizer by cement weight $(\% \mathrm{bcw})$. Accelerators dosages varied according to the type used. AKF 0.38 was used at $7.0 \%$, AKF 0.42 at $11.0 \%$, AKF 0.61 at $5.0 \%$ and $7.0 \%$ and ALK at $3.0 \%$ bcw. Those contents were determined according to the procedure described by [18] to assure equivalent mechanical performance in pastes and fall within the dosages usually applied in tunnels executed with sprayed material. Water contents of superplasticizer and accelerators were deducted from the total amount of mixing water in order to keep the final w/c ratio equal to 0.45 .

The composition of each matrix in terms of ions and compounds present is described in Table 6. An information of interest is the final $\mathrm{C}_{3} \mathrm{~A} / \mathrm{SO}_{3}$ ratio after accelerator addition. As the alkaline accelerator does not contain any sulfates in its composition, $\left[\mathrm{Al}(\mathrm{OH})_{4}\right]^{-}$consumes approximately $48 \%$ of the sulfate present in cement when added at $3.0 \%$ bcw. By doing so, the final $\mathrm{C}_{3} \mathrm{~A} / \mathrm{SO}_{3}$ ratio in the alkaline accelerated pastes is twice the initial value from cement. This causes a lack of sulfate ions to control $\mathrm{C}_{3} \mathrm{~A}$ hydration and the cement may hydrate as undersulfated [22]. This effect is less pronounced in the matrix containing AKF 0.38, because it presents the highest $\mathrm{Al}_{2} \mathrm{O}_{3} / \mathrm{SO}_{4}{ }^{2-}$ molar ratio.

Table 6 - Ionic composition in accelerated cement matrices.

\begin{tabular}{|c|c|c|c|c|c|}
\hline n (mmol/g cement) & $\begin{array}{c}\text { CEM I_AKF } \\
\text { 0.38 7\% / } \\
\text { CEM II/A-L } \\
\end{array}$ & $\begin{array}{c}\text { CEM I_AKF } \\
\text { 0.42 11\% / } \\
\text { CEM II/A-L } \\
\end{array}$ & $\begin{array}{c}\text { CEM I_AKF } \\
\text { 0.61 5\% / } \\
\text { CEM II/A-L } \\
\end{array}$ & $\begin{array}{c}\text { CEM I_AKF } \\
\text { 0.61 7\% / } \\
\text { CEM II/A-L } \\
\end{array}$ & $\begin{array}{c}\text { CEM I_ALK } \\
\text { 3\% / CEM } \\
\text { II/A-L } \\
\end{array}$ \\
\hline Total $\mathrm{SO}_{4}{ }^{2-}$ in cement ${ }^{\mathrm{a}}$ & $0.441 / 0.401$ & $0.441 / 0.401$ & $0.441 / 0.401$ & $0.441 / 0.401$ & $0.441 / 0.401$ \\
\hline $\mathrm{Al}$ in accelerator ${ }^{\mathrm{b}}$ & 0.154 & 0.218 & 0.132 & 0.185 & 0.141 \\
\hline $\mathrm{SO}_{4}{ }^{2-}$ in accelerator & 0.201 & 0.258 & 0.109 & 0.153 & - \\
\hline $\mathrm{H}^{+}$in accelerator & - & 0.046 & 0.117 & 0.163 & - \\
\hline $\mathrm{Na}^{+}$in accelerator & - & - & - & - & 0.184 \\
\hline Ettringite formed & 0.077 & 0.109 & 0.066 & 0.093 & 0.071 \\
\hline $\begin{array}{l}\mathrm{SO}_{4}^{2-} \text { consumed in } \\
\text { ettringite formation }\end{array}$ & 0.231 & 0.327 & 0.199 & 0.278 & 0.212 \\
\hline $\mathrm{SO}_{4}^{2-}$ left & 0.411 & 0.371 & 0.351 & 0.316 & 0.229 \\
\hline $\begin{array}{c}\text { Final } \mathrm{C}_{3} \mathrm{~A} / \mathrm{SO}_{3} \text { molar } \\
\text { ratio }^{\mathrm{c}}\end{array}$ & $0.42 / 0.36$ & $0.47 / 0.40$ & $0.50 / 0.42$ & $0.55 / 0.48$ & $0.76 / 0.70$ \\
\hline
\end{tabular}

a Determined by ion chromatography with a solution obtained from the dissolution of $1.00 \mathrm{~g}$ of cement in $10.0 \mathrm{~mL}$ of concentrated nitric acid, according to [23].

${ }^{\text {b }}$ Aluminum corresponds to $\mathrm{Al}^{3+}$ and $\left[\mathrm{Al}(\mathrm{OH})_{4}\right]^{-}$in alkali-free and alkaline accelerators, respectively. 
${ }^{c}$ The final $\mathrm{C}_{3} \mathrm{~A} / \mathrm{SO}_{3}$ ratio was calculated considering the sulfate amount remaining after accelerator reaction and the initial $\mathrm{C}_{3} \mathrm{~A}$ content of cements.

Cement pastes employed for in situ X-ray diffraction (XRD) were hand-mixed because the amount required for this test was approximately 4.0 grams. Water and superplasticizer were pre-mixed and the resulting solution was homogenized with cement by means of a vortex external mixer during 60 seconds. Accelerators were added to the pastes 1 hour after cement and water had been mixed. The resulting paste was vigorously homogenized for 15 seconds with a spatula. During the period between the mixing of cement and water and accelerator addition, the paste was kept at $20^{\circ} \mathrm{C}$ in order to avoid the influence of variations in temperature.

This procedure intends to reproduce the condition usually found in practice, since accelerator addition only occurs almost one hour after the mixing of the other components. Moreover, this also allows a clearer evaluation of the heat flow attributed to accelerator reaction, which otherwise would overlap with the initial heat released in the mixing of cement and water.

The amount of paste required for the determination of setting times and ultrasound propagation velocity was approximately 700 grams. Therefore, pastes could not be hand-mixed. Instead, they were prepared in a conventional mixer, adapting the procedures from UNE-EN 196-3:2005 [24]. Accelerators were also added 1 hour after cement and water had been mixed. The resulting paste was homogenized for 15 seconds at high speed. The molds for both tests were filled and consolidated manually right after accelerator homogenization.

Even though the preparation of pastes used for in situ XRD and ultrasound measurements were not the same, it does not limit the comparison of results. In each particular test, identical mixing procedures were employed for all the pastes. Therefore, the differences observed in their hydration behavior may be associated exclusively to the reactions between cements and accelerators.

\subsubsection{Mortars}

Mortars were prepared using a sand/cement ratio equal to $2.0, \mathrm{w} / \mathrm{c}$ ratio equal to 0.45 and superplasticizer at $1.0 \% \mathrm{bcw}$. Mortars contained the same accelerators dosages as cement pastes and also presented the composition shown in Table 6. Batches 
containing $2330 \mathrm{~g}$ were prepared in a conventional mortar mixer [21]. Accelerator addition and mold filling followed the same procedures as in cement pastes.

\subsection{Test methods}

Tests performed with cement pastes and mortars are shown in Table 7. Their descriptions are presented subsequently. Accelerator addition was considered as the beginning of all the tests.

Table 7 - Tests carried out with accelerated pastes and mortars.

\begin{tabular}{cccc}
\hline Test & Matrix & Period of time & Reference \\
\hline In situ XRD & Paste & $24 \mathrm{~h}$ & {$[25]$} \\
\hline Determination of setting times & Paste & Until final setting time & {$[24]$} \\
\hline $\begin{array}{c}\text { Determination of ultrasonic } \\
\text { wave propagation velocity }\end{array}$ & Paste and mortar & $24 \mathrm{~h}$ & {$[16]$} \\
\hline Evolution of temperature & Paste and mortar & $24 \mathrm{~h}$ & {$[18]$} \\
\hline
\end{tabular}

In situ XRD was performed with cement pastes to avoid the dilution of cement hydrated phases by the aggregate. Therefore, phases present in small amounts could be quantified. Equipment and experimental conditions adopted for this test and structure models used for Rietveld refinement are described in [25]. Amorphous content was determined by the internal standard method [26] to provide an indirect assessment of the $\mathrm{C}-\mathrm{S}-\mathrm{H}$ amount contained in the matrix.

Setting times were determined using an automatic Vicat penetrometer. Although the standard UNE EN 196-3 (2005) [24] prescribes the use of a normal consistency paste, a w/c equal to 0.45 was adopted to facilitate handling and molding of the accelerated pastes and because it generates enough space for proper cement hydration and crystal growth [20]. Moreover, when low w/c ratios are used $(0.27-0.32$, for example), initial setting occurs approximately 2 minutes after accelerator addition, even when superplasticizers are used [27]. This would make the paste unworkable before the mold was filled, leading to inaccuracies in the results.

Ultrasound wave (P-wave) propagation velocity was used to monitor the setting and hardening processes and the microstructure development in fresh accelerated cement pastes and mortars. The device used for this measurement is similar to the 
FreshCon system [28]. The container consists of two polymethacrylate walls with 22 mm-long spacers between them, where a U-shaped foam mold with an approximate volume of $140 \mathrm{~mL}$ is placed. On each exterior side of the container, a longitudinal wave transducer of $500 \mathrm{kHz}$ of central frequency is attached.

Ultrasonic P-waves are generated by a wireless sensor network named WilTempUS, developed by the G-CARMA research group [29]. This system is composed by a base and a mote that monitor temperature, relative humidity (T/RH) and ultrasonic velocity at same time. Two channels coupled with commercial SHT15 sensors from Sensirion Company were employed to measure the temperature of the environment and the evolution of temperature of the hydrating sample. This experiment was performed during 24 hours, with a recording interval of 10 seconds during the first 2 hours and of 1 minute after that.

Figure 1 shows the equipment used and the execution of the experiment. As tests were performed with accelerated cement matrices, shrinkage could cause the loss of contact between the matrix and the mold, interrupting the propagation of ultrasonic waves. To solve this problem, a coupling device formed by two springs pressing on the walls of the mold was used [30]. In addition, the equipment was placed inside a sealed plastic box with relative humidity above $95 \%$ to avoid decoupling. 


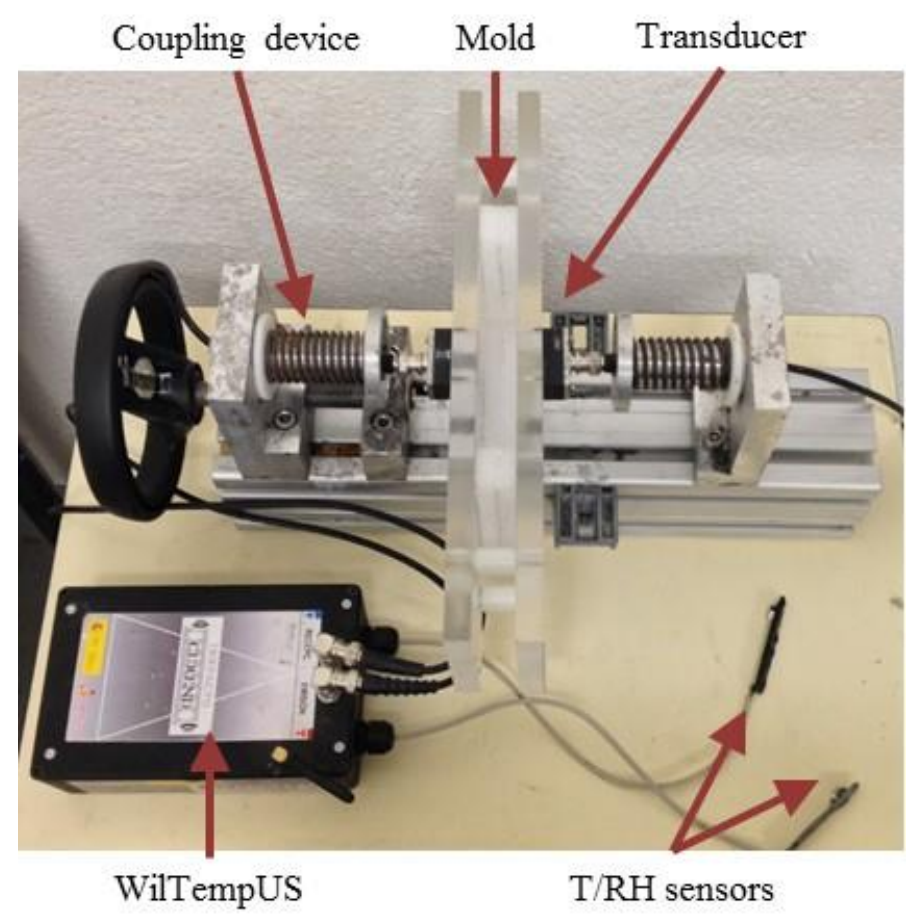

(a)

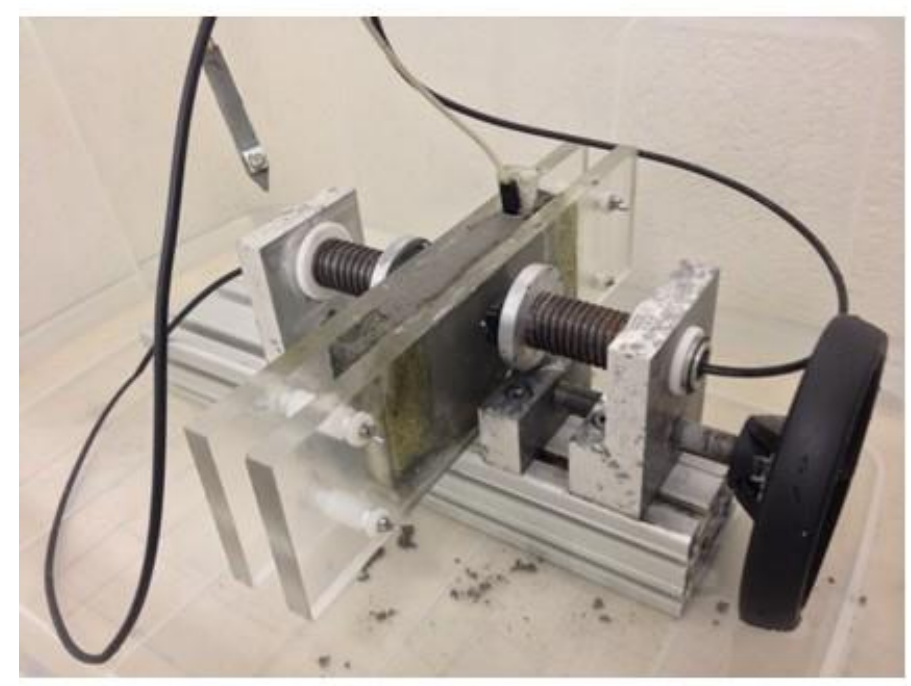

(b)

Figure 1 - Equipment for ultrasound measurements (a) and execution of the test (b).

\section{Results and discussion}

\subsection{In situ X-ray diffraction}

The evolution of phase composition in accelerated cement pastes measured by in situ X-ray diffraction is presented in Figure 2. In order to simplify the interpretation of 
the graphs, only the reacting phases (alite, portlandite and ettringite) are shown. Results obtained with CEM I pastes are grouped on the left and with CEM II/A-L are grouped on the right.

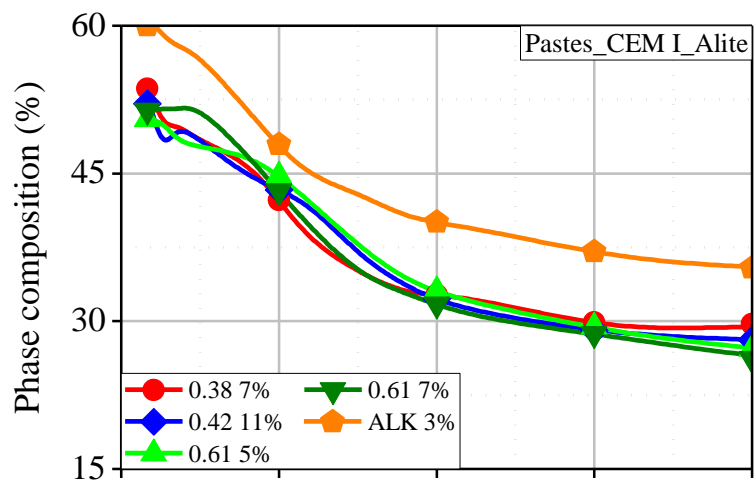

(a)

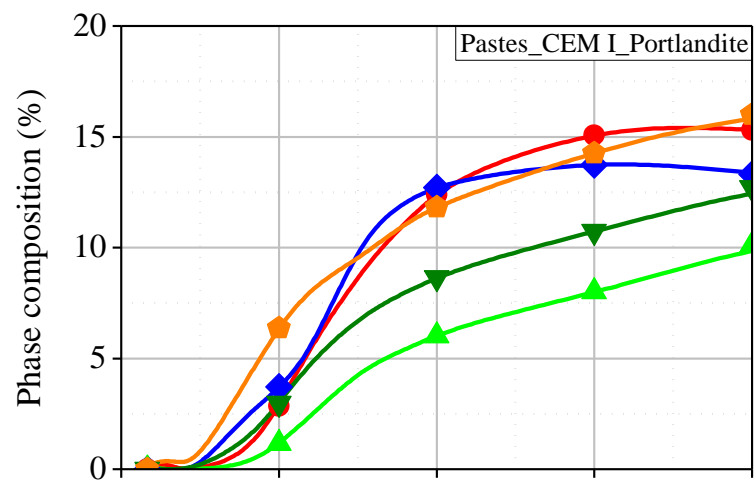

(c)

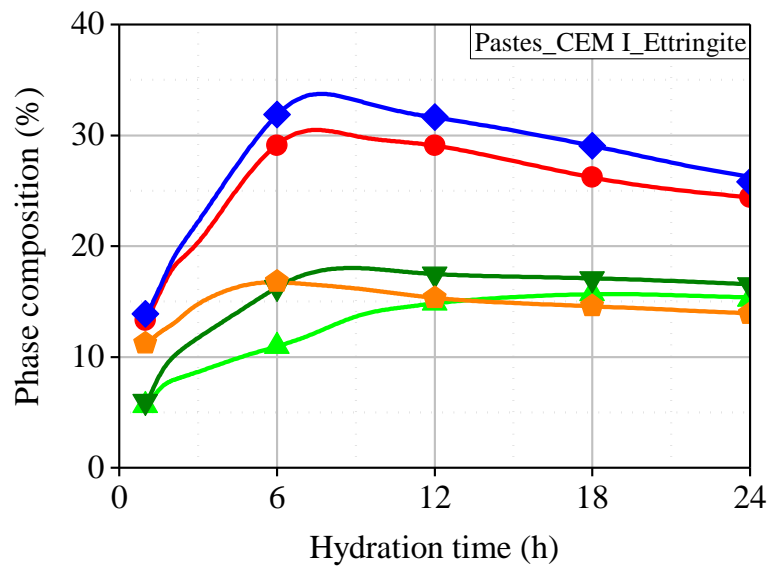

(e)

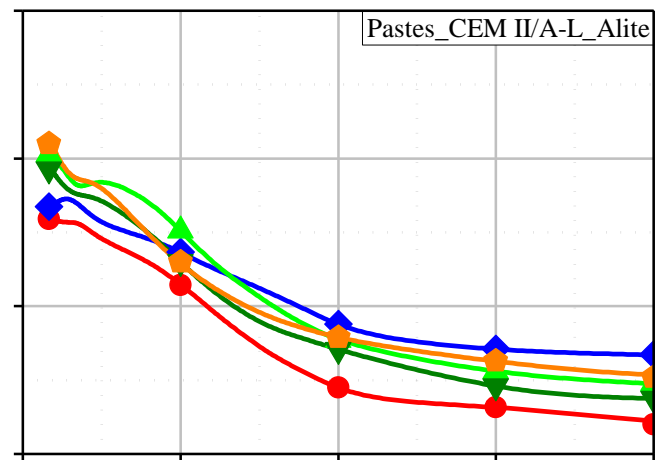

(b)

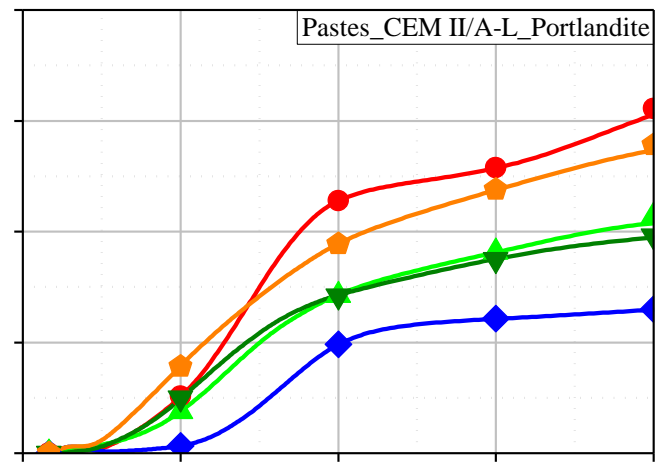

(d)

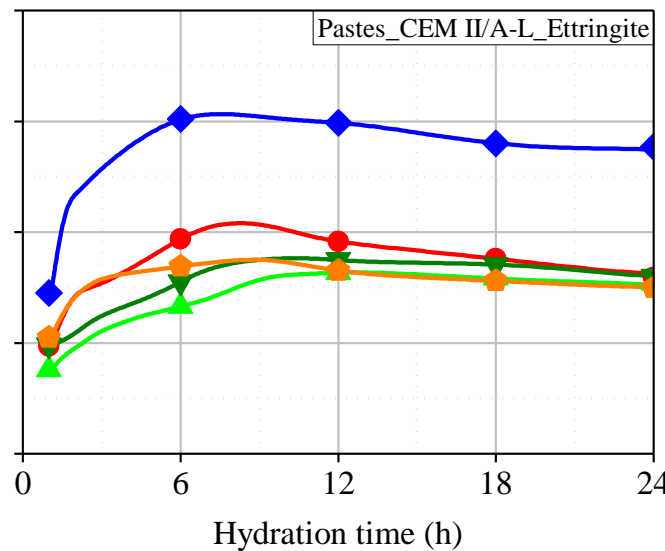

(f)

Figure 2 - Evolution of alite (a and b), portlandite (c and d) and ettringite (e and f) contents from 0 to $24 \mathrm{~h}$ in CEM I and CEM II/A-L pastes. (trocar cores)

Accelerator reaction leads to a massive precipitation of ettringite in all the pastes analyzed [25]. The amount of ettringite formed is directly proportional to the sum of $\mathrm{Al}^{3+}$ and $\mathrm{SO}_{4}{ }^{2-}$ contents in accelerators (AKF $0.4211 \%>\mathrm{AKF} 0.387 \%>\mathrm{AKF} 0.617 \%$ $>\mathrm{AKF} 0.615 \%$ ). The formation and growth of this hydrate rapidly increases the 
solid/liquid ratio of the matrix [31], interconnecting the solid phase. Therefore, short setting times and fast increases in ultrasound velocity are expected to be obtained with accelerators containing larger $\mathrm{Al}^{3+}$ amounts.

Alite dissolves slowly until 3 hours of hydration to balance $\mathrm{Ca}^{2+}$ concentration in the liquid phase, previously disturbed by accelerators. The rate of alite hydration in the main hydration process is indirectly proportional to the final $\mathrm{C}_{3} \mathrm{~A} / \mathrm{SO}_{3}$ ratio of the paste (AKF $0.387 \%>$ AKF $0.4211 \%>$ AKF $0.617 \%>$ AKF $0.615 \%$, Table 6). In properly sulfated pastes (produced with AKF 0.38 and AKF 0.42), the amount of sulfate remaining after accelerator reaction retards $\mathrm{C}_{3} \mathrm{~A}$ hydration, which occurs after the acceleration period and does not affect silicate hydration. On the contrary, as accelerator $\mathrm{AKF} 0.61$ provides the lowest sulfate content to the matrices, $\mathrm{C}_{3} \mathrm{~A}$ hydration is accelerated and the matrix is filled with aluminate hydrated products before the onset of the main hydration process. As a result, the rate of alite hydration is reduced during the acceleration period [32,33].

After the acceleration period, alite dissolution and portlandite precipitation are significantly influenced by accelerator reactivity. The large amounts of ettringite precipitated by accelerators containing high $\mathrm{Al}^{3+}$ concentrations fill up the space available quickly, decreasing the extent of alite hydration. Pastes produced with AKF $0.4211 \%$ present the lowest degrees of silicate hydration at 24 hours, while pastes containing AKF $0.615 \%$ present constant alite consumption and portlandite formation from 12 hours on.

The alkaline accelerator reactivity is higher than AKF $0.615 \%$ and lower than the other accelerators, due to its aluminum concentration (Table 6). Besides, the rate of ettringite formation is the lowest because this accelerator does not contain any sulfate in its formulation. Therefore, accelerator reactivity is limited by gypsum dissolution and AFm phases are formed at the moment of accelerator addition [25]. As CEM II_ALK $3 \%$ has a lower final $\mathrm{C}_{3} \mathrm{~A} / \mathrm{SO}_{3}$ ratio than the equivalent CEM I paste (Table 6) and contains limestone filler, $\mathrm{C}_{3} \mathrm{~A}$ hydration is postponed and ettringite consumption is retarded.

Initial alite dissolution in alkaline accelerated pastes is favored because this accelerator contains $\mathrm{NaOH}$, which leads to a fast portlandite precipitation [34]. However, the high final $\mathrm{C}_{3} \mathrm{~A} / \mathrm{SO}_{3}$ ratio in these matrices promotes accelerated undersulfated $\mathrm{C}_{3} \mathrm{~A}$ reactions, with consequent formation of $\mathrm{AFm}$ phases before or during alite hydration. This process increases reaction rate in the acceleration period, 
but delays alite hydration after 8 hours, because the early formed aluminate hydrates fill up the space in the matrix and decrease the solubility of silicate phases $[25,35]$.

\subsection{Setting times}

Figure 3 presents setting times determined with cement pastes. Results obtained vary considerably in pastes with and without accelerators. Cement hydration in reference pastes is significantly retarded by the superplasticizer, increasing setting times.

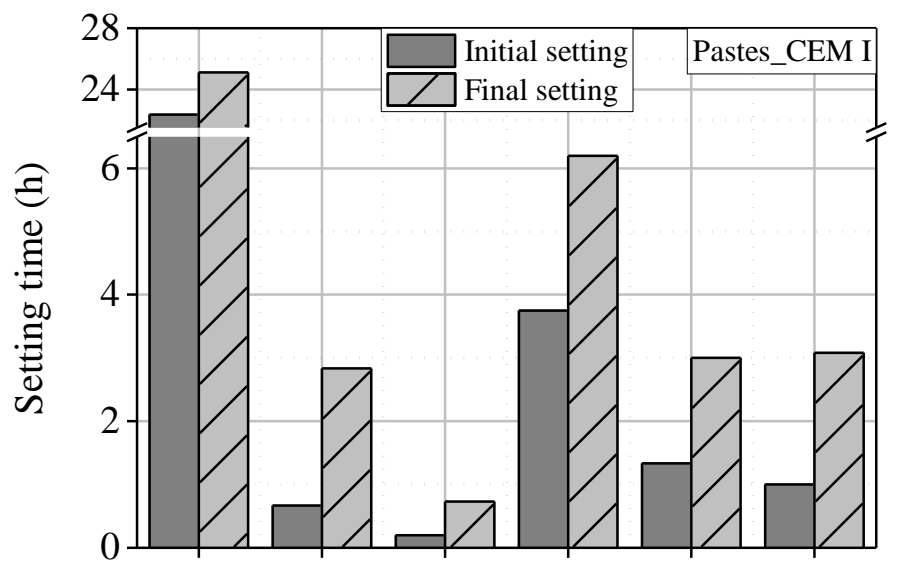

(a)

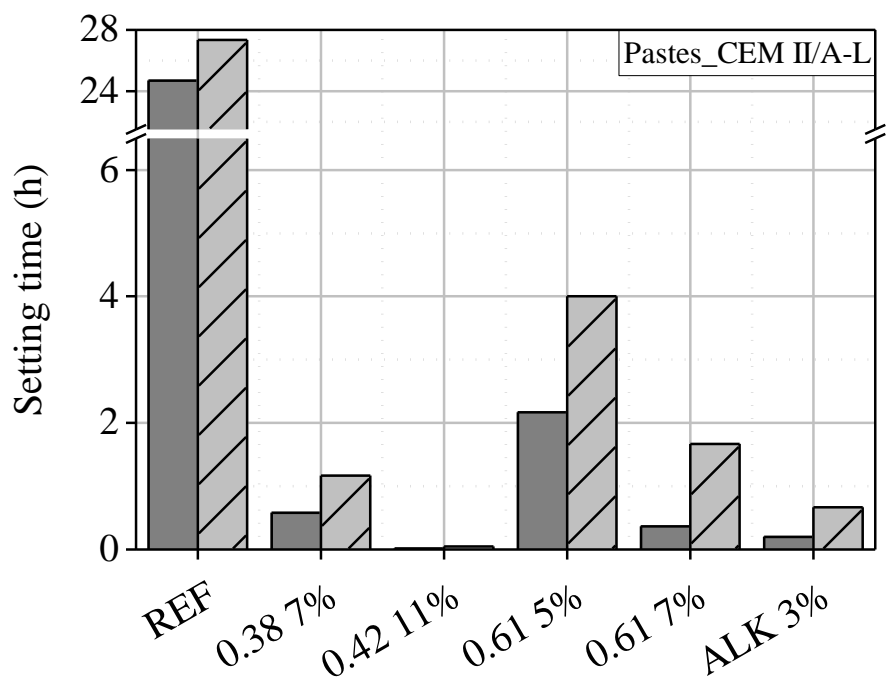

Accelerator and dosage

(b)

Figure 3 - Setting times determined with CEM I (a) and CEM II/A-L (b) pastes.

Setting times are reduced in accelerated pastes and depend on cement type, accelerator type and dosage. Pastes produced with CEM II/A-L present shorter setting 
times than equivalent CEM I pastes. Limestone filler reacts with aluminum ions from accelerators, forming AFm phases [27]. Moreover, as cement is diluted by the filler addition, a larger space is available for the precipitation of hydrates [36]. Both processes contribute to reduce setting times.

As observed in in situ XRD (section 3.1), the amount of ettringite formed in accelerated pastes is directly proportional to $\mathrm{Al}^{3+}$ concentration in accelerators. Since ettringite is the main product that leads to initial mechanical strength in the matrices evaluated, the larger the amount of ettringite formed by accelerator reaction, the shorter the setting times of the pastes. Therefore, the ascending order of setting times is AKF $0.4211 \%<$ ALK $3 \%<$ AKF $0.387 \%<$ AKF $0.617 \%<$ AKF $0.615 \%<$ REF.

\subsection{Ultrasound wave propagation velocity and evolution of temperature}

\subsubsection{Influence of phase evolution during hydration on the ultrasound velocity}

Figure 4 and Figure 5 present the P-wave velocity, evolution of temperature and phase composition of pastes CEM I_AKF 0.42 11\% and CEM II_AKF 0.61 5\%, respectively. Theses pastes were selected because they presented the fastest and the slowest kinetics of hydration, respectively. The results of all the tests are presented altogether in order to recognize the main chemical processes that influence ultrasound propagation in the hydrating matrix. The stages identified in each picture are explained subsequently. 


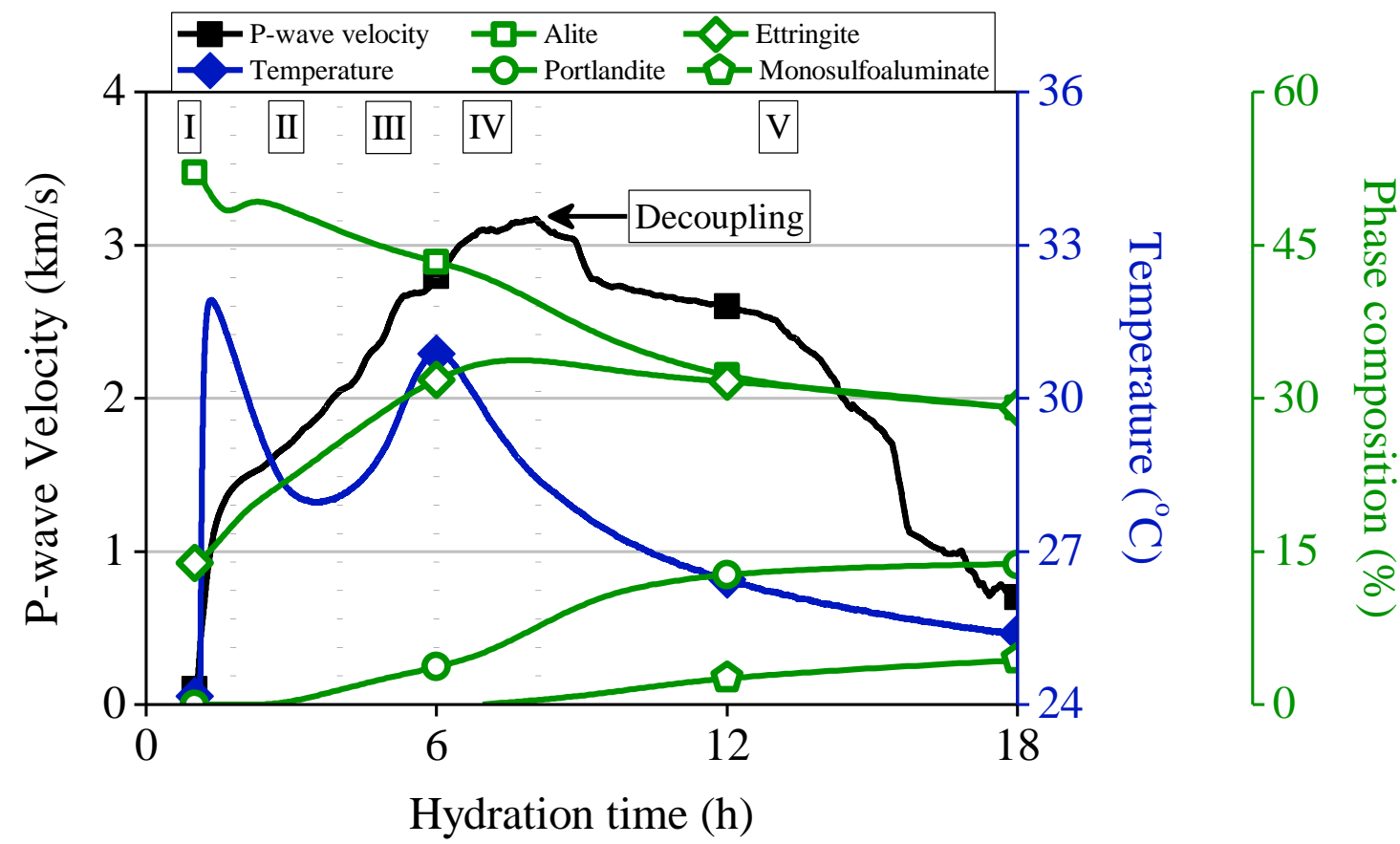

Figure 4 - Evolution of P-wave velocity, temperature and phase composition of paste CEM I_ALK 0.42 $11 \%$.

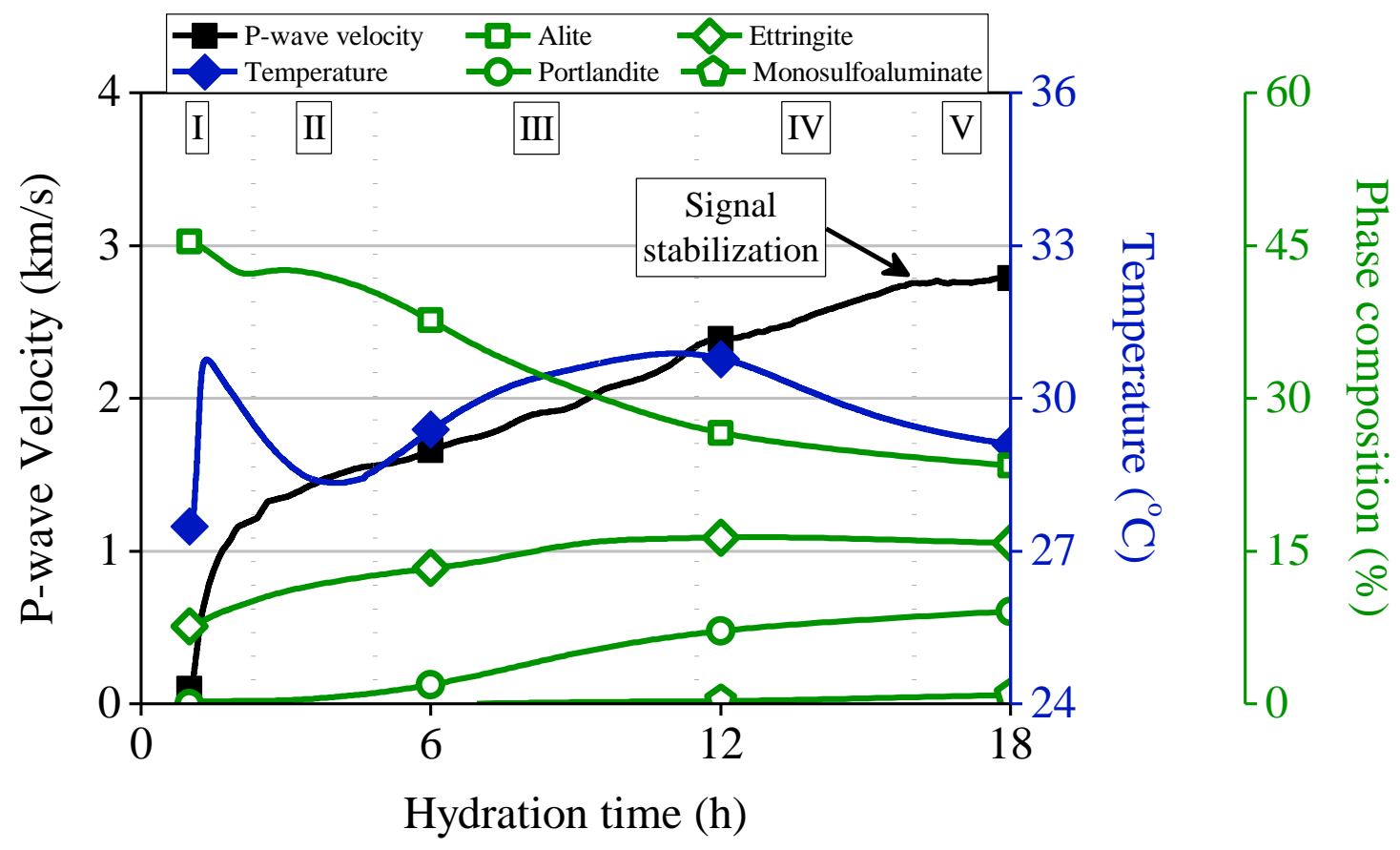

Figure 5 - Evolution of P-wave velocity, temperature and phase composition of paste CEM II_AKF 0.61 $5 \%$.

- Stage I - accelerator reaction: Fast exothermic ettringite precipitation caused by accelerator reaction. This process increases the solid/liquid ratio of the matrix and improves the solid phase connectivity quickly. As a result, a sharp increase in 
ultrasound propagation velocity occurs, proportionally to accelerator reactivity. Alite dissolution is minimal and does not contribute to increase P-wave velocity.

- Stage II - induction period: The rate of ettringite formation decreases, consequently reducing the slope of ultrasound velocity curve at 1.8 and 2.3 hours in CEM I_AKF $0.4211 \%$ and CEM II_AKF $0.615 \%$, respectively. The temperature of the pastes also reduces due to low reaction rates. The extent of alite consumption and portlandite precipitation is low and does not influence propagation velocity.

- Stage III - acceleration period: The onset of alite hydration occurs, with consequent precipitation of portlandite and C-S-H. $\mathrm{C}_{3} \mathrm{~A}$ hydration continues, as observed by the constant formation of ettringite. As hydration progresses and microstructure develops, the solid particles interconnectivity improves and the porosity of the matrix decreases. As a result, a constant increase in ultrasound propagation velocity is observed, which is directly proportional to the temperature rise of the matrix and to the rate of alite consumption.

- Stage IV - deceleration period: Hydration rate starts to decelerate, leading to reductions in temperature and in the rate of increase of ultrasound propagation velocity.

- Stage V - deceleration period: The transition from stage IV to stage V is accompanied by an inflection point in P-wave velocity. The test was interrupted in paste CEM I_AKF $0.4211 \%$ at around 8 hours, due to the shrinkage of the paste and consequent decoupling of transducers. The loss of contact between the mold and the matrix coincides with the beginning of ettringite conversion to monosulfoaluminate. As ettringite has a relative low density and high molecular volume when compared to AFm phases [37,38], its consumption by $\mathrm{C}_{3} \mathrm{~A}$ and $\mathrm{C}_{4} \mathrm{AF}$ hydrations leads to matrix shrinkage. This process happens mainly in CEM I pastes, due to its high $\mathrm{C}_{3} \mathrm{~A}$ content, and when accelerators containing high aluminum concentrations are employed, because large ettringite amounts are produced. In these cases, pore filling caused by $\mathrm{C}-\mathrm{S}-\mathrm{H}$ and portlandite formation does not compensate the shrinkage originated by ettringite consumption.

In paste CEM II_AKF $0.615 \%$, decoupling of transducers does not occur. Instead, ultrasound velocity stabilizes and remains constant after the beginning of stage V. As ettringite is indirectly stabilized by limestone filler [19] and its consumption occurs at a lower rate and extent than in paste CEM I_AKF $0.4211 \%$, the reduction in the 
volume of aluminate hydrated phases is smaller. Therefore, shrinkage does not cause the loss of contact between mold walls and the matrix and ultrasound measurements continue.

\subsubsection{General results of cement pastes and mortars}

Figure 6 and Figure 7 present the P-wave velocity and the evolution of temperature of cement pastes and mortars, respectively. Results obtained with CEM I are grouped on the left and with CEM II/A-L are grouped on the right. Discussion is presented subsequently, organized by matrix type, cement type and accelerator type and dosage.

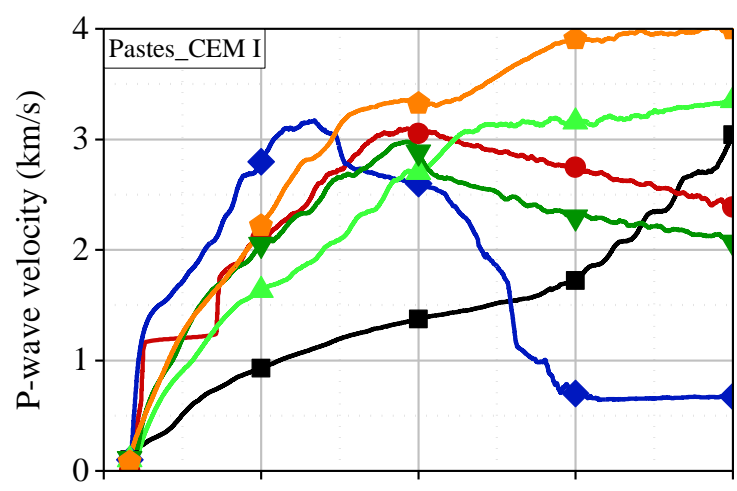

(a)

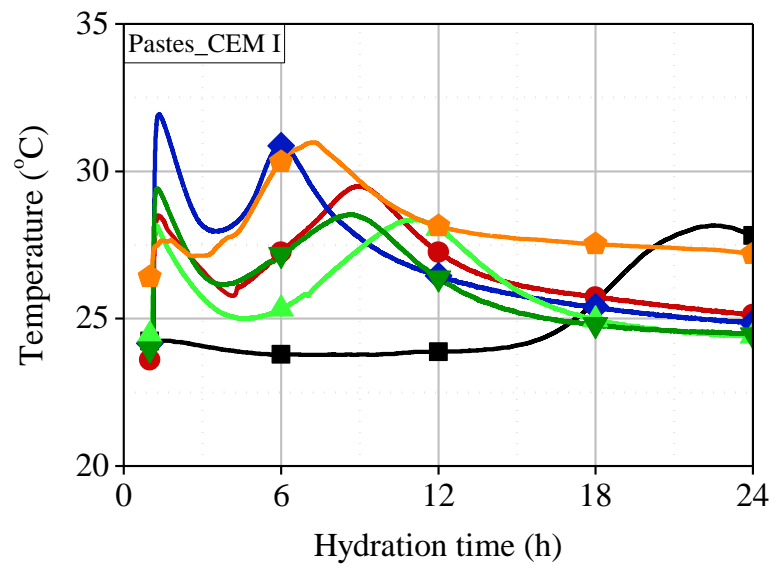

(c)

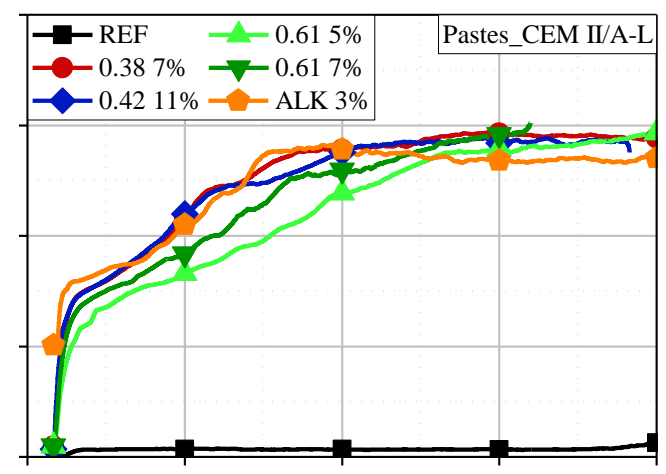

(b)

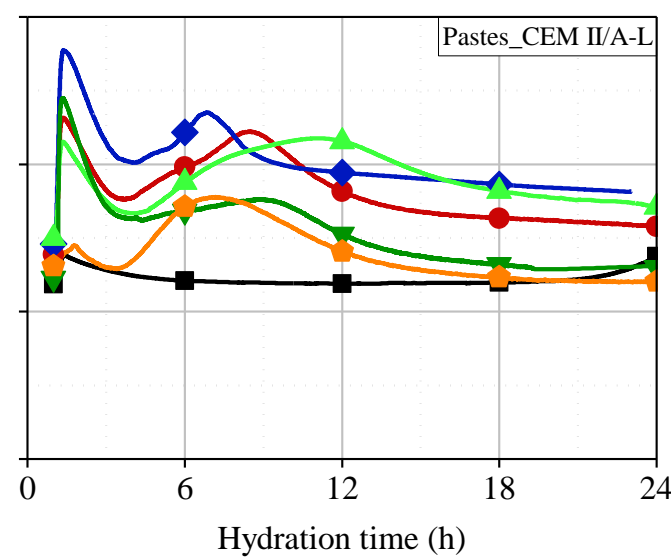

(d)

Figure 6 - Evolution of P-wave velocity ( $a$ and $b$ ) and temperature (c and d) in CEM I and CEM II/A-L pastes. 


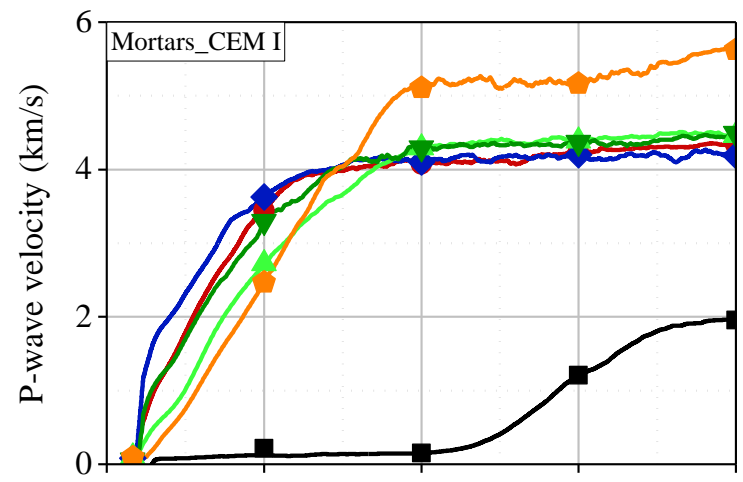

(a)

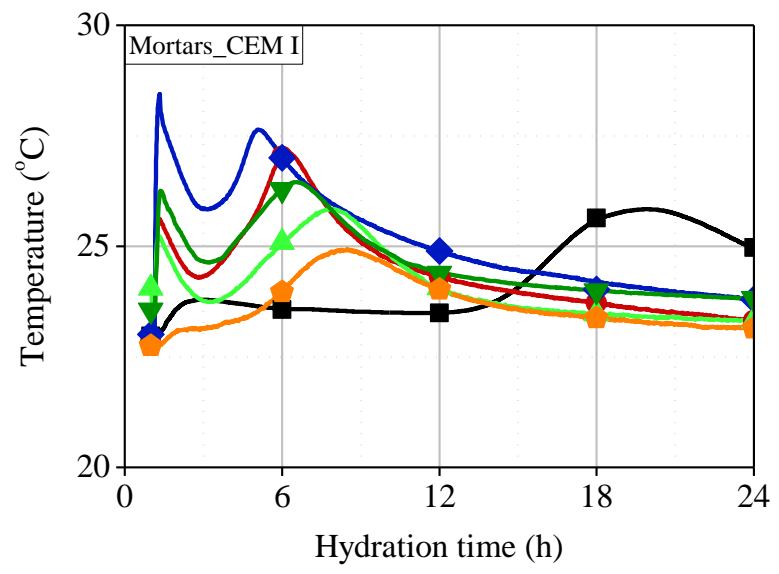

(c)

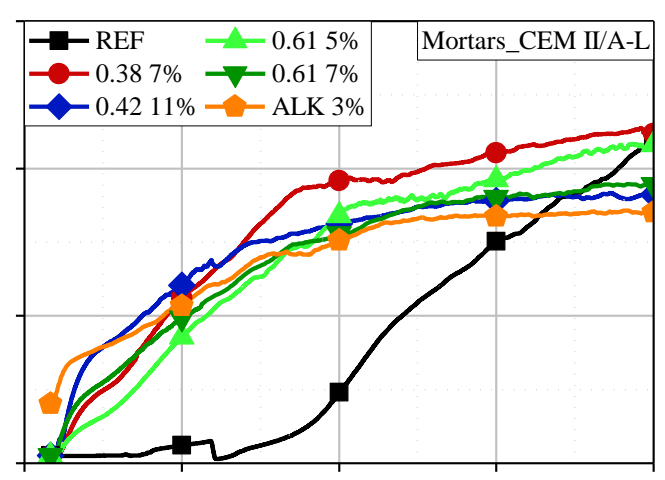

(b)

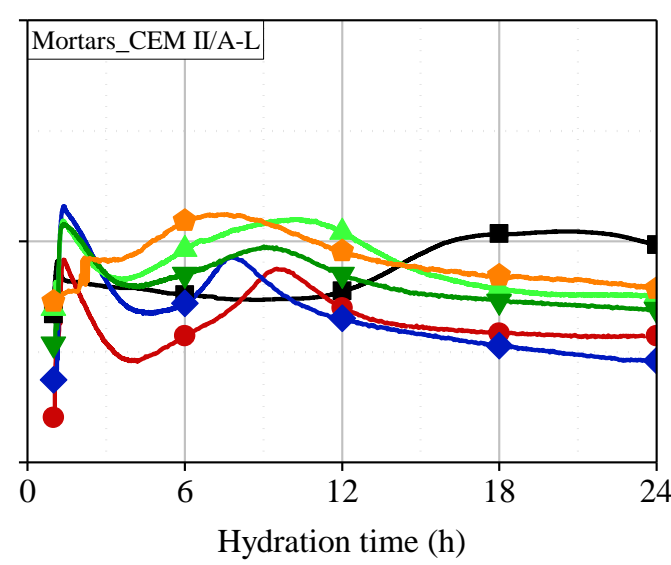

(d)

Figure 7 - Evolution of P-wave velocity ( $a$ and b) and temperature (c and d) in CEM I and CEM II/A-L mortars.

\section{Matrix type}

Accelerator reactivity may be evaluated equally in either pastes or mortars. As pastes are constituted by more reactive systems, reaction kinetics are faster and a more resolved differentiation of the chemical processes occurring in the hydrating matrix is achieved. However, the shrinkage of pastes is more intense, which may lead to decoupling of transducers and interrupt the progression of the test when accelerators containing high $\mathrm{Al}^{3+}$ concentrations are used.

In mortars, aggregates dilute cement and accelerator and provide more space for hydration to occur. Therefore, shrinkage does not negatively affect the progression of the test and uninterrupted measurements are obtained. The development of microstructure derived from cement hydration and the reduction in porosity are clearer when mortars are employed. In reference mortars, the main hydration process starts earlier than in reference cement pastes because aggregates increase the shearing during mixing and accelerate cement hydration [39]. 


\section{Cement type}

Accelerator reactivity is improved in CEM II/A-L matrices. Since this cement contains $23 \%$ less $\mathrm{C}_{3} \mathrm{~A}$ than CEM I (Table 2), more sulfate is available to react with aluminum ions from accelerators and ettringite formation is favored. As discussed in section 3.2, limestone filler reacts with aluminum ions from accelerators [27] and provides a larger space for the precipitation of hydrates [36], increasing the ultrasound propagation velocity. These processes also contribute to avoid the decoupling of transducers. As can be observed in Figure 6.b, no decoupling occurred in CEM II/A-L pastes because the rate of ettringite conversion to AFm phases is lower than in equivalent CEM I pastes (Figure 2.e).

CEM I matrices present faster hydration kinetics because this cement contains more alite (Table 2) and is finer than CEM II/A-L (Table 4). Therefore, the rate of ultrasound velocity increase and the maximum velocity reached after the acceleration period are intensified. However, decoupling occurs more often due to the faster ettringite consumption by $\mathrm{C}_{3} \mathrm{~A}$ hydration (section 3.1). The ultrasound velocity curve in pastes CEM I_AKF 0.38 7\%,CEM I_AKF $0.4211 \%$ and CEM I_AKF 0.61 7\% were interrupted after the deceleration period.

\section{Accelerator type and dosage}

Hydration of pastes and mortars without accelerator is significantly retarded by the superplasticizer. Induction periods in these matrices are long and the main hydration process starts approximately at 14 hours in mortars and after 18 hours in pastes. The beginning of ultrasound velocity increase coincides with the onset of the main hydration peak in the curves of evolution of temperature.

In accelerated matrices, $\mathrm{P}$-wave velocity depends on accelerator reactivity and is directly proportional to the amount of $\mathrm{Al}^{3+}$ added to the matrix. Matrices produced with AKF $0.4211 \%$ present the highest values of ultrasound velocity in the first stage because this accelerator produces the largest amount of ettringite and, therefore, the largest solid phase interconnectivity. On the contrary, pastes and mortars CEM I_AKF $0.615 \%$ and CEM II_AKF $0.615 \%$ present the lowest rate of ultrasound velocity increase, as $\mathrm{AKF} 0.61$ used at $5.0 \% \mathrm{bcw}$ is the least reactive accelerator and provides 
the lowest amount of $\mathrm{Al}^{3+}$ ions. The descending order of ultrasound velocity in stage $\mathrm{I}$ is AKF $0.4211 \%>$ AKF $0.617 \%>$ AKF $0.387 \%>$ AKF $0.615 \%$, which is the reverse order observed in the determination of setting times.

During the acceleration period, the rate of ultrasound velocity increase is directly proportional to the degree of hydration of alite and $\mathrm{C}_{3} \mathrm{~A}$ and to the evolution of temperature of the matrix. In systems presenting low $\mathrm{C}_{3} \mathrm{~A} / \mathrm{SO}_{3}$ ratios (when accelerators AKF 0.38 and AKF 0.42 are employed) alite hydration is responsible for ultrasound velocity increase. Besides, the formation of $A F m$ phases by accelerated $\mathrm{C}_{3} \mathrm{~A}$ reactions in matrices containing AKF 0.61 and ALK also contribute to increase US velocity during the main hydration process.

Ultrasound velocity curves of mortars (Figure 7.a and Figure 7.b) indicate that accelerators that provide a sharp initial velocity increase tend to reduce the maximum velocity reached after the beginning of the deceleration period. On the contrary, accelerators containing low $\mathrm{Al}^{3+}$ concentrations lead to a low increase in ultrasound velocity due to accelerator reaction, but the maximum velocity reached after the main hydration peak is above the values of the other mortars. The first case is exemplified by mortars CEM I and CEM II_AKF $0.4211 \%$ and the second case occurs with CEM I and CEM II_AKF $0.615 \%$. The ascending order of ultrasound velocity in stage V in CEM I mortars is AKF $0.4211 \%<$ AKF $0.387 \%<$ AKF $0.617 \%<$ AKF $0.615 \%$, which is the same order observed in the determination of setting times.

The main reason for this fact is that matrices produced with accelerators containing high $\mathrm{Al}^{3+}$ concentrations stiffen quickly and do not consolidate properly [18]. As a consequence, they present higher porosities, which decrease ultrasound velocity. In contrast, setting times in matrices containing low reactive accelerators are longer, which leads to a better consolidation. Therefore, ultrasound propagation in the deceleration period is enhanced and its velocity increases.

In addition, since the elastic modulus of AFm phases is respectively 2 and 3.5 times higher than ettringite and C-S-H $\left(\mathrm{E}_{\mathrm{AFm}}=42.3 \mathrm{GPa}\right.$ [40], $\mathrm{E}_{\text {Ettringite }}=22.4 \mathrm{GPa}$ [40], $\left.\mathrm{E}_{\mathrm{C}-\mathrm{S}-\mathrm{H}}=12.0 \mathrm{GPa}[41]\right)$, undersulfated systems may lead to higher P-wave velocities during stage $\mathrm{V}$. AFm phases formed by $\mathrm{C}_{3} \mathrm{~A}$ hydration increase ultrasound velocity, which is directly proportional to the elastic modulus of the matrix [7]. This is the case of CEM I paste and mortar produced with the alkaline accelerator $\left(\mathrm{C}_{3} \mathrm{~A} / \mathrm{SO}_{3}\right.$ ratio equal to 0.76, Table 6). 
Paste and mortar CEM II_ALK 3\% present a different behavior from the equivalent CEM I matrices. Since the alkaline accelerator does not contain any sulfate in its formulation, aluminate ions react with calcium ions and limestone filler, forming monosulfoaluminate, hemi and monocarboaluminate [25]. This phases fill up the pores and increase the elastic modulus of the matrix quickly. Therefore, ultrasound velocity increases sharply, faster than in pastes and mortars containing alkali-free accelerators. However, as the early formation of AFm phases limits further alite hydration, CEM II_ALK 3\% matrices present the lowest increase in ultrasound velocity from the acceleration period on.

\subsubsection{Comparison with final setting times}

Table 8 presents the final setting times and the ultrasound velocity of accelerated cement pastes at the time of final set. The average ultrasound velocity for CEM I pastes is $(1.54 \pm 0.09) \mathrm{km} / \mathrm{s}$ and for CEM II/A-L pastes is $(1.53 \pm 0.05) \mathrm{km} / \mathrm{s}$. These results indicate that final set occurs when ultrasound velocity reaches $1.5 \mathrm{~km} / \mathrm{s}$, approximately. Paste CEM II_AKF $0.4211 \%$ deviates from this behavior due to the high accelerator reactivity and consequent difficulties in molding operations (this paste was not used for the calculation of average results).

Table 8 - Comparison of final setting times and ultrasound velocity in accelerated cement pastes.

\begin{tabular}{ccc}
\hline Paste & $\begin{array}{c}\text { Final setting } \\
\text { time (h) }\end{array}$ & $\begin{array}{c}\text { US velocity at final } \\
\text { setting time (km/s) }\end{array}$ \\
\hline CEM I_AKF 0.38 7\% & 2.8 & 1.48 \\
\hline CEM I_AKF 0.42 11\% & 0.73 & 1.39 \\
\hline CEM I_AKF 0.61 5\% & 6.1 & 1.64 \\
\hline CEM I_AKF 0.61 7\% & 3.0 & 1.59 \\
\hline CEM I_ALK 3\% & 3.1 & 1.59 \\
\hline CEM II_AKF 0.38 7\% & 1.2 & 0.30 \\
\hline CEM II_AKF 0.42 11\% & 0.050 & 1.57 \\
\hline CEM II_AKF 0.61 5\% & 4.0 & 1.46 \\
\hline CEM II_AKF 0.61 7\% & 1.7 & 1.58 \\
\hline CEM II_ALK 3\% & 0.67 & \\
\hline
\end{tabular}


The results shown in Table 8 are in accordance with Reinhardt and Grosse [28], who reported that final set could be determined by ultrasound velocities of $1.50 \mathrm{~km} / \mathrm{s}$. This value may also be adopted to determine final setting times in accelerated matrices.

Initial setting could not be correlated to ultrasound velocity because the equipment used in this research employs $\mathrm{P}$-waves. Transversal waves ( $\mathrm{S}$-waves) should be used to characterize initial setting times [1].

\section{Multivariate regression analyses}

In this section, general models to predict ultrasound propagation velocity in accelerated matrices were developed based on multivariate regression analyses. P-wave velocities in mortars were selected as the standard dependent variables, because the results obtained with pastes were negatively affected by shrinkage and consequent decoupling of transducers. They were divided in three stages (accelerator reaction: from accelerator addition until $3 \mathrm{~h}$; acceleration period: from 5 to $11 \mathrm{~h}$; and deceleration period: from 13 hours on) in order to provide a more meaningful analysis.

The independent variables correspond to the chemical properties of cement and accelerators and phase composition of pastes determined by in situ XRD. The most statistically significant independent variables were selected by analyses of variance (pvalues below 0.05, confidence level above $95 \%$ ) and are shown in Table 9. Although only two cement types were evaluated, limestone filler was adopted as an independent variable because it improves all the fitted models. These parameters are considered appropriate based on principles of accelerators, cement and hydration chemistry. Results are presented from sections 4.1 to 4.4 .

Table 9 - Selection of statistically significant variables influencing P-wave velocity.

\begin{tabular}{cc}
\hline P-wave velocity stage & Independent variables \\
\hline Accelerator reaction & $\begin{array}{c}\text { Time, ettringite content in paste, aluminum and sulfate } \\
\text { contents in accelerator, filler content in cement }\end{array}$ \\
\hline Acceleration period & $\begin{array}{c}\text { Time, amorphous, ettringite and } \mathrm{AFm} \text { contents in } \\
\text { paste, filler content in cement }\end{array}$ \\
\hline Deceleration period & $\begin{array}{c}\text { Amorphous, ettringite and } \mathrm{AFm} \text { contents in paste, filler } \\
\text { content in cement, final } \mathrm{C}_{3} \mathrm{~A} / \mathrm{SO}_{3} \text { ratio }\end{array}$ \\
\hline
\end{tabular}

\subsection{Accelerator reaction}


The parameters used to model ultrasound velocity generated by accelerator reaction, their coefficients and p-values are presented in Table 10. The best-fit model obtained is represented in Equation 1. Figure 8 represents a plot of the experimentally determined ultrasound velocity versus the values predicted by the model.

Table 10 - Parameters selected to model ultrasound velocity increase due to accelerator reaction.

\begin{tabular}{|c|c|c|c|}
\hline Parameter & Abbreviation & Coefficient & P-value \\
\hline Constant & - & -1.53 & $<0.001$ \\
\hline Time (h) & $\mathrm{t}$ & 0.826 & 0.001 \\
\hline$(\text { Time })^{2}$ & $\mathrm{t}^{2}$ & -0.195 & 0.025 \\
\hline Ettringite content in paste $(\%)$ & $\mathrm{E}$ & 0.0286 & 0.001 \\
\hline $\begin{array}{l}\text { Aluminum content in accelerator }(\mathrm{mmol} / \mathrm{g} \\
\text { cement) }\end{array}$ & $\mathrm{Al}$ & 6.35 & $<0.001$ \\
\hline $\begin{array}{l}\text { Sulfate content in accelerator }(\mathrm{mmol} / \mathrm{g} \\
\text { cement) }\end{array}$ & $\bar{S}$ & 1.76 & 0.018 \\
\hline Filler content in cement $(\%)$ & $\mathrm{F}$ & 0.101 & $<0.001$ \\
\hline Time-Sulfate content in accelerator & $\mathrm{t} \cdot \bar{S}$ & 1.76 & $<0.001$ \\
\hline Time $\cdot$ Filler content in cement & $\mathrm{t} \cdot \mathrm{F}$ & -0.0199 & 0.017 \\
\hline $\begin{array}{c}\text { Sulfate content in accelerator } \text { Filler content in } \\
\text { cement }\end{array}$ & $\bar{S} \cdot \mathrm{F}$ & -0.695 & $<0.001$ \\
\hline
\end{tabular}

$\underset{(\mathrm{km} / \mathrm{s})}{\mathrm{V}_{\mathrm{US}}}=\begin{gathered}-1.53+0.826 \cdot \mathrm{t}-0.195 \cdot \mathrm{t}^{2}+0.0286 \cdot \mathrm{E}+6.35 \cdot \mathrm{Al}+1.76 \cdot \bar{S}+ \\ 0.101 \cdot \mathrm{F}+1.76 \cdot \mathrm{t} \cdot \bar{S}-0.0199 \cdot \mathrm{t} \cdot \mathrm{F}-0.695 \cdot \bar{S} \cdot \mathrm{F}\end{gathered} \quad$ Equation 1

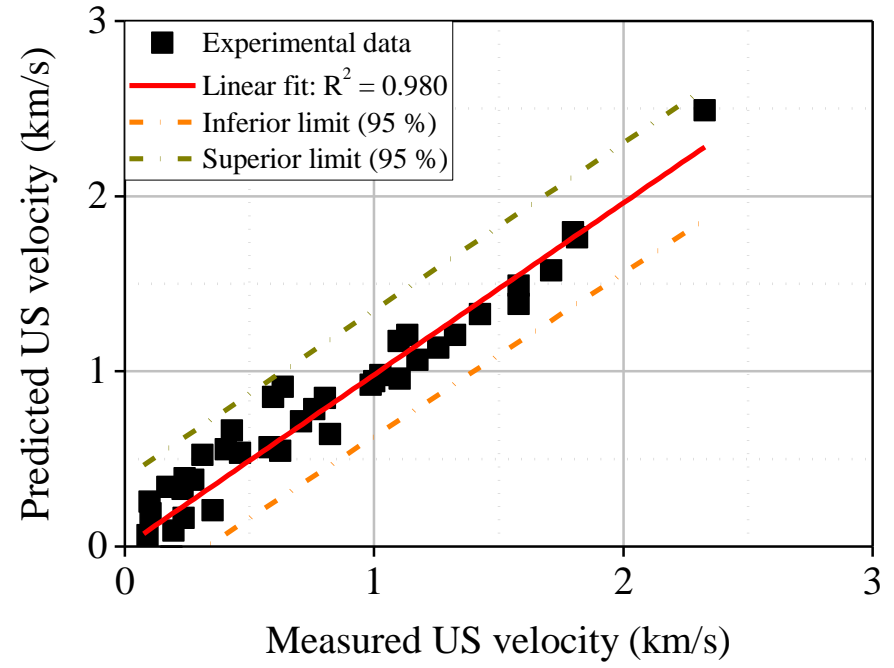

Figure 8 - Plot of measured versus predicted ultrasound propagation velocity due to accelerator reaction. 
An overall $\mathrm{R}^{2}$ value of 0.980 was achieved, demonstrating that the model proposed provides a statistically significant prediction of the measured results. It indicates that ultrasound velocity increases with time, depends majorly on accelerator reactivity and is influenced by limestone filler, in accordance with the discussion in section 3.3.2.

Furthermore, the model demonstrates that P-wave velocity is a function of ettringite amount produced by accelerator addition. Since ettringite is the main product that leads to solid phase interconnection, the larger the amount of ettringite formed by accelerator reaction, the higher the ultrasound velocity in the matrix. The use of high dosages of accelerators and formulations containing high concentrations of aluminum and sulfate contribute to form ettringite, reducing setting times and increasing the rate of ultrasound velocity growth.

\subsection{Acceleration period}

The parameters used to model ultrasound velocity during the acceleration period, their coefficients and p-values are presented in Table 11. The final model obtained is shown in Equation 2. Figure 9 represents a plot of the measured versus predicted ultrasound velocity.

Table 11 - Parameters used to model ultrasound velocity increase during the acceleration period.

\begin{tabular}{cccc}
\hline Parameter & Abbreviation & Coefficient & P-value \\
\hline Constant & - & 0.603 & 0.045 \\
\hline Time $(\mathrm{h})$ & $\mathrm{t}$ & 0.385 & $<0.001$ \\
\hline Amorphous phases content in paste $(\%)$ & $\mathrm{Am}$ & 0.136 & 0.014 \\
\hline Ettringite content in paste $(\%)$ & $\mathrm{E}$ & 0.0343 & $<0.001$ \\
\hline Filler content in cement $(\%)$ & $\mathrm{F}$ & -0.0976 & $<0.001$ \\
\hline (AFm phases content in paste) ${ }^{2}(\%)$ & $\mathrm{AFm}{ }^{2}$ & 0.440 & $<0.001$ \\
\hline Time. Amorphous phases content in paste & $\mathrm{t} \cdot \mathrm{Am}$ & -0.0214 & 0.009 \\
\hline $\begin{array}{c}\text { Ettringite content in paste-AFm phases } \\
\text { content in paste }\end{array}$ & $\mathrm{E} \cdot \mathrm{AFm}$ & -0.0417 & $<0.001$ \\
\hline
\end{tabular}

$$
\begin{array}{cc}
\mathrm{V}_{\mathrm{US}} & 0.603+0.385 \cdot \mathrm{t}+0.136 \cdot \mathrm{Am}+0.0343 \cdot \mathrm{E}-0.0976 \cdot \mathrm{F}+ \\
(\mathrm{km} / \mathrm{s}) & 0.44 \cdot \mathrm{AFm}^{2}-0.0214 \cdot \mathrm{t} \cdot \mathrm{Am}-0.0417 \cdot \mathrm{E} \cdot \mathrm{AFm}
\end{array}
$$




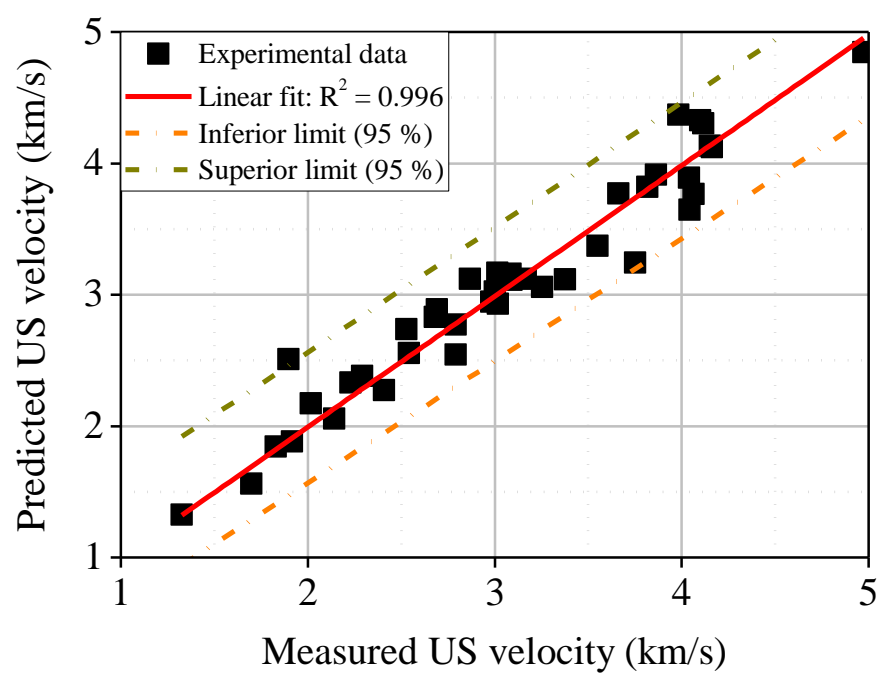

Figure 9 - Plot of measured versus predicted ultrasound propagation velocity during acceleration period.

The fitted model presents an $\mathrm{R}^{2}$ value equal to 0.996 and suggests a high correlation between measured and predicted ultrasound velocity during the acceleration period. It indicates that $\mathrm{P}$-wave velocity depends on accelerator reaction, alite and $\mathrm{C}_{3} \mathrm{~A}$ hydrations.

Ultrasound velocity is directly proportional to C-S-H and ettringite contents in the matrix, because these phases determine the solid phase interconnectivity. Moreover, undersulfated systems present higher pulse velocities, as AFm phases formed by $\mathrm{C}_{3} \mathrm{~A}$ hydration increase the elastic modulus of the matrix (section 3.3.2). Since limestone filler postpones $\mathrm{C}_{3} \mathrm{~A}$ hydration, it contributes to lower ultrasound propagation velocity during the acceleration period.

\subsection{Deceleration period and signal stabilization}

The parameters used to model ultrasound velocity during the deceleration period, their coefficients and p-values are presented in Table 12. Equation 3 represents the final model obtained. Figure 10 shows a plot of the experimentally determined ultrasound velocity versus the values predicted by the model.

Table 12 - Parameters selected to model ultrasound velocity increase during the deceleration period.

\begin{tabular}{llll}
\hline Parameter & Abbreviation & Coefficient & P-value \\
\hline
\end{tabular}




\begin{tabular}{cccc}
\hline Constant & - & 4.81 & $<0.001$ \\
\hline Ettringite content in paste (\%) & $\mathrm{E}$ & -0.0540 & $<0.001$ \\
\hline AFm phases content in paste (\%) & $\mathrm{AFm}$ & 0.236 & 0.001 \\
\hline Filler content in cement (\%) & $\mathrm{F}$ & 0.132 & $<0.001$ \\
\hline${\text { (Final } \mathrm{C}_{3} \mathrm{~A} / \mathrm{SO}_{3} \text { ratio) }}^{2}$ & $(\mathrm{C} / \bar{S})^{2}$ & 2.07 & 0.001 \\
\hline $\begin{array}{c}\text { Amorphous phases content in paste } \cdot \mathrm{AFm} \\
\text { phases content in paste }\end{array}$ & $\mathrm{Am} \cdot \mathrm{AFm}$ & -0.124 & 0.001 \\
\hline \begin{tabular}{c} 
Filler content in cement $\cdot$ Final $\mathrm{C}_{3} \mathrm{~A} / \mathrm{SO}_{3}$ ratio \\
\hline
\end{tabular} & $\mathrm{F} \cdot \mathrm{C} / \overline{\mathrm{S}}$ & -0.433 & $<0.001$ \\
\hline
\end{tabular}

$\begin{array}{ccc}\mathrm{V}_{\mathrm{US}} \\ (\mathrm{km} / \mathrm{s})\end{array}=\begin{array}{cc}4.81-0.0540 \cdot \mathrm{E}+0.236 \cdot \mathrm{AFm}+0.132 \cdot \mathrm{F}+2.07 \cdot(\mathrm{C} / \bar{S})^{2}- & \\ 0.124 \cdot \mathrm{Am} \cdot \mathrm{AFm}-0.433 \cdot \mathrm{F} \cdot \mathrm{C} / \bar{S} & \text { Equation 3 }\end{array}$

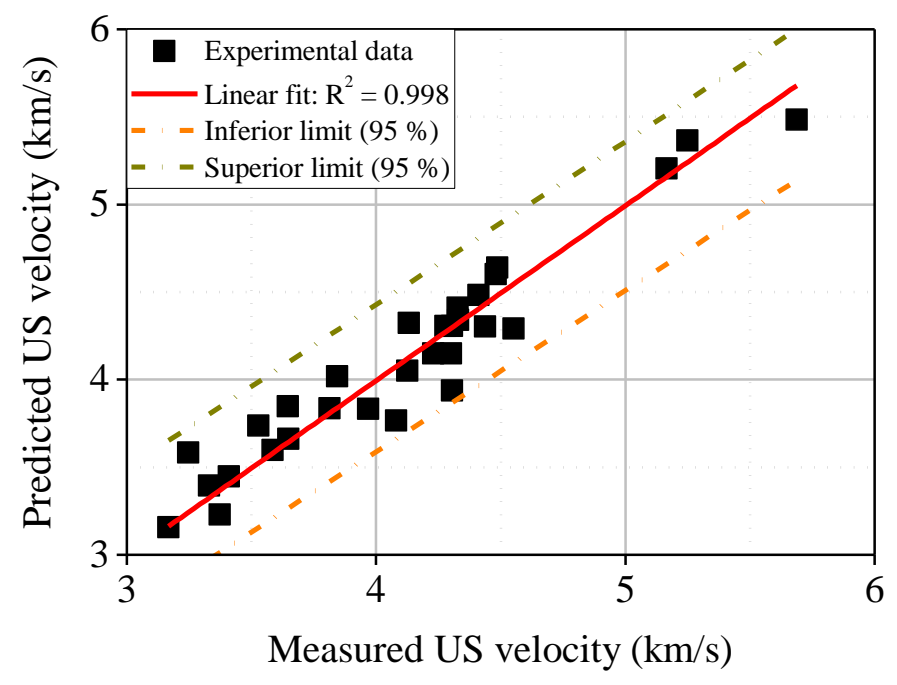

Figure 10 - Plot of measured versus predicted ultrasound propagation velocity during deceleration period.

A high correlation between experimental and predicted data was obtained $\left(\mathrm{R}^{2}=\right.$ 0.998). This model indicates that undersulfated systems (high $\mathrm{C}_{3} \mathrm{~A} / \mathrm{SO}_{3}$ ratios) present higher ultrasound propagation velocities than properly sulfated matrices, due to their larger amounts of AFm phases and lower contents of ettringite and C-S-H (section 3.3.2). This corroborates the fact the accelerators ALK and AKF 0.61 lead to higher ultrasound propagation velocities than accelerators AKF 0.38 and 0.42. In addition, since limestone filler leads to the formation of hemi and monocarboaluminate, it also favors ultrasound propagation.

\subsection{Summary}


Table 13 presents a summary of the parameters studied and their influence on the overall ultrasound wave propagation velocity.

Table 13 - Summary of the variables evaluated and their influence on ultrasound propagation velocity.

\begin{tabular}{ccccc}
\hline \multirow{2}{*}{ Parameter } & Change & \multicolumn{3}{c}{ Effect on P-wave propagation velocity } \\
\cline { 3 - 5 } & & $\begin{array}{c}\text { Accelerator } \\
\text { reaction }\end{array}$ & $\begin{array}{c}\text { Acceleration } \\
\text { period }\end{array}$ & $\begin{array}{c}\text { Deceleration } \\
\text { period }\end{array}$ \\
\hline $\begin{array}{c}\mathrm{Al}^{3+} \text { in accelerator or } \\
\text { accelerator dosage }\end{array}$ & $\uparrow$ & $\uparrow \uparrow \uparrow$ & - & - \\
\hline $\mathrm{SO}_{4}{ }^{2-}$ in accelerator & $\uparrow$ & $\uparrow$ & - & - \\
\hline $\begin{array}{c}\text { Ettringite amount } \\
\text { formed by accelerator }\end{array}$ & $\uparrow$ & $\uparrow \uparrow$ & $\uparrow$ & $\downarrow$ \\
\hline $\begin{array}{c}\text { Filler content in } \\
\text { cement }\end{array}$ & $\uparrow$ & $\uparrow$ & $\downarrow$ & $\uparrow$ \\
\hline $\begin{array}{c}\text { Amorphous }(\mathrm{C}-\mathrm{S}-\mathrm{H}) \\
\text { content }\end{array}$ & $\uparrow$ & - & $\uparrow \uparrow$ & $\downarrow$ \\
\hline $\mathrm{AFm}^{2}$ content & $\uparrow$ & - & $\uparrow \uparrow$ & $\uparrow \uparrow \uparrow$ \\
\hline \begin{tabular}{c} 
Final $\mathrm{C}_{3} \mathrm{~A} / \mathrm{SO}_{3}$ ratio \\
\hline
\end{tabular} & $\uparrow$ & - & - & $\uparrow \uparrow$ \\
\hline
\end{tabular}

\section{Conclusions}

Based on the results obtained from the experimental program conducted, the following conclusions may be drawn:

- Ultrasound measurements provide a clear and continuous evaluation of setting, hardening and microstructure development during hydration of accelerated cement matrices. The technique employed was sensitive to cement composition, accelerator type and dosage and could distinguish hydration stages. It is an interesting tool for research and development of new accelerator formulations.

- Initial microstructure development is governed by accelerator reactivity. Ettringite formed by accelerator reaction increases the solid/liquid ratio of the matrix and 
improves the solid phase connectivity quickly. Consequently, ultrasound velocity increases sharply and is directly proportional to aluminum content in accelerators.

- Increase of P-wave velocity during the acceleration period is directly proportional to hydration rates. As alite and $\mathrm{C}_{3} \mathrm{~A}$ hydrate, forming respectively $\mathrm{C}-\mathrm{S}-\mathrm{H}$ and $\mathrm{AFm}$ phases, ultrasound velocity increases.

- When accelerators containing high aluminum contents are employed, the matrix stiffens quickly and does not consolidate properly. For that reason, the porosity of the matrix is high and P-wave velocity during the deceleration period is reduced.

- Undersulfated systems present higher ultrasound velocities during the deceleration period than properly sulfated matrices. $\mathrm{C}_{3} \mathrm{~A}$ hydration in the absence of sulfates leads to higher ultrasound velocities because the elastic modulus of AFm phases is 2 and 3.5 times higher than the elastic modulus of ettringite and C-S-H, respectively.

- Limestone filler decreases ultrasound velocity in the acceleration period because it retards $\mathrm{C}_{3} \mathrm{~A}$ hydration. However, P-wave velocity increases in the deceleration period in CEM II/A-L matrices because limestone leads to the formation of hemi and monocarboaluminate and provides a larger space for the precipitation of hydrates.

- Decoupling of transducers in cement pastes is associated with ettringite conversion to monosulfoaluminate. As AFm phases are denser than ettringite, their formation leads to matrix shrinkage and to the consequent loss of contact between the matrix and mold walls. Decoupling occurs mainly when cements contain large $\mathrm{C}_{3} \mathrm{~A}$ amounts and no limestone filler and when high $\mathrm{Al}^{3+}$ contents are employed.

- Final setting times may be determined when P-wave velocity reaches $1.5 \mathrm{~km} / \mathrm{s}$.

- Correlations between ultrasound propagation velocity in mortars and their chemical properties and phase composition were established. All regressions presented $\mathrm{R}^{2}$ superior than 0.980 , indicating that the models developed provide statistically significant predictions of the experimental results.

\section{Acknowledgements}

The first author would like to thank CAPES (CAPES Foundation, Ministry of Education of Brazil, process 2726/13-0) for the scholarship granted. This research was 
possible due to the project RTC-2015-3185-4 (MAPMIT), co-funded by the Ministerio de Economía y Competitividad of Spain in the Call Restos-Colaboración 2015 and by the European Union through FEDER funds under the objective of promoting the technological development, innovation and high quality research. Thanks for technical and financial support are extended to Industrias Químicas del Ebro, to Centro para el Desarrollo Industrial (CDTi) and to the Ministerio de Economía y Competitividad, all of them in the context of the project IDI-20130248. We also thank Dr. Xavier Alcobé for his support during the XRD experiments.

\section{References}

[1] J. Carette, S. Staquet, Monitoring the setting process of mortars by ultrasonic P and S-wave transmission velocity measurement, Constr. Build. Mater. 94 (2015) 196-208. doi:10.1016/j.conbuildmat.2015.06.054.

[2] G. Trtnik, M.I. Valic, G. Turk, Measurement of setting process of cement pastes using non-destructive ultrasonic shear wave reflection technique, NDT\&E Int. 56 (2013) 65-75. doi:10.1016/j.ndteint.2013.02.004.

[3] N. Robeyst, C.U. Grosse, N. De Belie, Monitoring fresh concrete by ultrasonic transmission measurements: Exploratory multi-way analysis of the spectral information, Chemom. Intell. Lab. Syst. 95 (2009) 64-73. doi:10.1016/j.chemolab.2008.08.005.

[4] T. Voigt, G. Ye, Z. Sun, S.P. Shah, K. Van Breugel, Early age microstructure of Portland cement mortar investigated by ultrasonic shear waves and numerical simulation, Cem. Concr. Res. 35 (2005) 858-866. doi:10.1016/j.cemconres.2004.09.004.

[5] T. Voigt, Y. Akkaya, S.P. Shah, Determination of early age mortar and concrete strength by ultrasonic wave reflections, ASCE J. Mater. Civ. Eng. 15 (2003) 247-254. doi:10.1061/(ASCE)0899-1561(2003)15:3(247).

[6] M. Molero, I. Segura, M.G. Hernández, M.A.G. Izquierdo, J.J. Anaya, Characterization of mortar samples using ultrasonic scattering attenuation, Phys. Procedia. 3 (2010) 839-845. doi:10.1016/j.phpro.2010.01.108.

[7] Z. Lafhaj, M. Goueygou, A. Djerbi, M. Kaczmarek, Correlation between porosity, permeability and ultrasonic parameters of mortar with variable water/cement ratio and water content, Cem. Concr. Res. 36 (2006) 625-633. doi:10.1016/j.cemconres.2005.11.009. 
[8] F.J. Juanes, L.G. Ullate, J.J. Anaya, NDE ultrasonic methods to characterize the porosity of mortar, NDT\&E Int. 34 (2001) 557-562. doi:10.1016/S09638695(01)00020-2.

[9] M.G. Hernández, J.J. Anaya, T. Sanchez, I. Segura, Porosity estimation of aged mortar using a micromechanical model, Ultrasonics. 44 (2006) e1007-e1011. doi:10.1016/j.ultras.2006.05.195.

[10] M. Molero, S. Aparicio, G. Al-Assadi, M.J. Casati , M.G. Hernández, J.J. Anaya, Evaluation of freeze-thaw damage in concrete by ultrasonic imaging, NDT\&E Int. 52 (2012) 86-94. doi:10.1016/j.ndteint.2012.05.004.

[11] I. Segura, M. Molero, S. Aparicio, J.J. Anaya, A. Moragues, Decalcification of cement mortars: Characterization and modelling, Cem. Concr. Compos. 35 (2013) 136150. doi:10.1016/j.cemconcomp.2012.08.015.

[12] H. Von Daake, D. Stephan, Setting of cement with controlled superplasticizer addition monitored by ultrasonic measurements and calorimetry, Cem. Concr. Compos. 66 (2016) 24-37. doi:10.1016/j.cemconcomp.2015.11.004.

[13] H.K. Lee, K.M. Lee, Y.H. Kim, H. Yim, D.B. Bae, Ultrasonic in-situ monitoring of setting process of high-performance concrete, Cem. Concr. Res. 34 (2004) 631-640. doi:10.1016/j.cemconres.2003.10.012.

[14] N. Robeyst, E. Gruyaert, C.U. Grosse, N. De Belie, Monitoring the setting of concrete containing blast-furnace slag by measuring the ultrasonic p-wave velocity, Cem. Concr. Compos. 38 (2008) 1169-1176. doi:10.1016/j.cemconres.2008.04.006.

[15] G. Trtnik, G. Turk, Influence of superplasticizers on the evolution of ultrasonic Pwave velocity through cement pastes at early age, Cem. Concr. Res. 51 (2013) 22-31. doi:10.1016/j.cemconres.2013.04.007.

[16] N. De Belie, C.U. Grosse, J. Kurz, H. Reinhardt, Ultrasound monitoring of the influence of different accelerating admixtures and cement types for shotcrete on setting and hardening behaviour, 35 (2005) 2087-2094. doi:10.1016/j.cemconres.2005.03.011.

[17] D. Lootens, M. Hansson, L. Oblak, B. Lindlar, Ultrasonic wave propagation for strength measurements: applications in shotcrete. In: $7^{\text {th }}$ International Symposium on Sprayed Concrete. Sandefjord, Norway, June/2014.

[18] I. Galobardes, Characterization and control of wet-mix sprayed concrete with accelerators. Ph.D. Thesis (2013). 
[19] B. Lothenbach, G.L. Saout, E. Gallucci, K.L. Scrivener, Influence of limestone on the hydration of Portland cements, Cem. Concr. Res. 38 (2008) 848-860. doi:10.1016/j.cemconres.2008.01.002.

[20] H.F.W. Taylor, Cement Chemistry, 2nd ed. Thomas Telford Publishing. 1997.

[21] AENOR, UNE-EN 196-1:2005. Method of testing cement - Parte 1: Determination of strength, 2005.

[22] A. Quennoz, K.L. Scrivener, Interactions between alite and $\mathrm{C}_{3} \mathrm{~A}$-gypsum hydrations in model cements, Cem. Conc. Res. 44 (2013) 46-54. doi:10.1016/j.cemconres.2012.10.018.

[23] AENOR. UNE-EN 196-2:2014. Method of testing cement - Part 2: Chemical analysis of cement, 2014.

[24] AENOR. UNE-EN 196-3:2005. Method of testing cement - Part 3: Determination of setting times and soundness, 2005.

[25] R.P. Salvador, S.H.P. Cavalaro, I. Segura, A.D. Figueiredo, J. Pérez, Early age hydration of cement pastes with alkaline and alkali-free accelerators for sprayed concrete, Constr. Build. Mater. $111 \quad$ (2016) 386-398. doi:10.1016/j.conbuildmat.2016.02.101.

[26] I.C. Madsen, N.V.Y. Scarlett, A. Kern, Description and survey of methodologies for the determination of amorphous content via X-ray powder diffraction, Zeitschrift Für Krist. 226 (12) (2011) 944-955. doi:10.1524/zkri.2011.1437.

[27] R.P. Salvador, S.H.P. Cavalaro, A. Rueda, A.D. Figueiredo, Effect of cement composition on the reactivity of alkali-free accelerating admixtures for shotcrete. In: $7^{\text {th }}$ International Symposium on Sprayed Concrete. Sandefjord, Norway, June/2014: pp. 350-360.

[28] H.W. Reinhardt, C.U. Grosse, Continuous monitoring of setting and hardening of mortar and concrete, Constr. Build. Mater. 18 (2004) 145-154. doi:10.1016/j.conbuildmat.2003.10.002.

[29] S. Aparicio, J. Ranz, R. Fernández, V. Albert, J. V Fuente, M.G. Hernández, Nondestructive monitoring of curing process in precast concrete, IOP Conf. Ser. Mater. Sci. Eng. 42 (2012) 12050. 
[30] J.R. García, Caracterización no destructiva del proceso de curado en materiales cementicios. Ph.D. Thesis (2015).

[31] C. Maltese, C. Pistolesi, A. Bravo, T. Cerulli, D. Salvioni, M. Squinzi, Formation of nanocrystals of AFt phase during the reaction between alkali-free accelerators and hydrating cement: a key factor for sprayed concretes setting and hardening, RILEM Proc. PRO 45 (2005) 329-338.

[32] H. Minard, S. Garrault, L. Regnaud, A. Nonat, Mechanisms and parameters controlling the tricalcium aluminate reactivity in the presence of gypsum, Cem. Concr. Res. 37 (2007) 1418-1426. doi:10.1016/j.cemconres.2007.06.001.

[33] S. Pourchet, L. Regnaud, J.P. Perez, A. Nonat, Early $\mathrm{C}_{3} \mathrm{~A}$ hydration in the presence of different kinds of calcium sulfate, Cem. Concr. Res. 39 (2009) 989-996. doi:10.1016/j.cemconres.2009.07.019.

[34] A. Kumar, G. Sant, C. Patapy, C. Gianocca, K.L. Scrivener, The influence of sodium and potassium hydroxide on alite hydration: Experiments and simulations, Cem. Concr. Res. 42 (2012) 1513-1523. doi:10.1016/j.cemconres.2012.07.003.

[35] P. Juilland, Early hydration of cementitious systems. Ph.D. Thesis (2009).

[36] E. Berodier, K. Scrivener, Understanding the filler effect on the nucleation and growth of C-S-H, J. Am. Ceram. Soc. 12 (2014) 3764-3773. doi:10.1111/jace.13177.

[37] B. Lothenbach, T. Matschei, G. Möschner, F.P. Glasser, Thermodynamic modelling of the effect of temperature on the hydration and porosity of Portland cement, Cem. Conc. Res. 38 (2008) 1-18. doi:10.1016/j.cemconres.2007.08.017.

[38] T. Matschei, B. Lothenbach, F.P. Glasser, Thermodynamic properties of Portland cement hydrates in the system $\mathrm{CaO}-\mathrm{Al}_{2} \mathrm{O}_{3}-\mathrm{SiO}_{2}-\mathrm{CaSO}_{4}-\mathrm{CaCO}_{3}-\mathrm{H}_{2} \mathrm{O}$, Cem. Concr. Res. 37 (2007) 1379-1410. doi:10.1016/j.cemconres.2007.06.002.

[39] P. Juilland, A. Kumar, E. Gallucci, R.J. Flatt, K.L. Scrivener, Effect of mixing on the early hydration of alite and OPC systems, Cem. Concr. Res. 42 (2012) 1175-1188. doi:10.1016/j.cemconres.2011.06.011.

[40] S. Kamali, M. Moranville, E. Garboczi, S. Prené, B. Gerard, Hydrate dissolution influence on the Young's modulus of cement pastes, in: Proc. 5th Int. Conf. Fract. Mech. Concr. Concr. Struct. Vail, USA, 2004, 631-638. 
[41] G. Constantinides, F.-J. Ulm, The effect of two types of C-S-H on the elasticity of cement-based materials: Results from nanoindentation and micromechanical modeling, Cem. Concr. Res. 34 (2004) 67-80. doi:10.1016/S0008-8846(03)00230-8. 